\title{
A Comparison of Blood Plasma Exosome Enrichment Strategies for Proteomic Analysis
}

\section{Natalie P. Turner}

Queensland University of Technology

Pevindu Abeysinghe

Queensland University of Technology

Keith A. Kwan Cheung

Queensland University of Technology

Kanchan Vaswani

Queensland University of Technology

Jayden Logan

Queensland University of Technology

Pawel Sadowski

Central Analytical Research Facility, QUT

Murray D. Mitchell ( $\square$ murray.mitchell@qut.edu.au )

Queensland University of Technology

\section{Research Article}

Keywords: Exosome, isolation, enrichment, ultracentrifugation, size-exclusion chromatography, ultrafiltration, mass-spectrometry, proteomics, extracellular vesicles

Posted Date: September 2nd, 2021

DOI: https://doi.org/10.21203/rs.3.rs-819042/v1

License: (c) (i) This work is licensed under a Creative Commons Attribution 4.0 International License.

Read Full License 


\section{A comparison of blood plasma exosome enrichment strategies for}

2 proteomic analysis.

3

4 Natalie P. Turner ${ }^{1,2}$, Pevindu Abeysinghe ${ }^{1,2}$, Keith A. Kwan Cheung ${ }^{1,2}$, Kanchan Vaswani ${ }^{1}$, Jayden $5 \operatorname{Logan}^{1,2}$, Pawel Sadowski ${ }^{3}$ and Murray D. Mitchell ${ }^{1,2 *}$.

6 Queensland University of Technology (QUT) ${ }^{1}$, Centre for Children's Health Research (CCHR), 62 Graham Street, 7 South Brisbane, QLD 4101; School of Biomedical Sciences (SBMS) ${ }^{2}$, QUT, Kelvin Grove Campus, Victoria Park Rd, 8 Kelvin Grove, QLD 4059; Central Analytical Research Facility (CARF) ${ }^{3}$, QUT, 2 George St, Brisbane City QLD 4000

10 Author emails:

11 Natalie P. Turner - natalie.turner@hdr.qut.edu.au

12 Pevindu Abeysinghe - abeysinghe.abeysingh@hdr.qut.edu.au

13 Keith A. Kwan Cheung - k.kwancheung@hdr.qut.edu.au

14 Kanchan Vaswani-k2.vaswani@qut.edu.au

15 Jayden Logan-jayden.logan@qut.edu.au

16 Pawel Sadowski - pawel.sadowski@qut.edu.au

17 Murray D. Mitchell - murray.mitchell@qut.edu.au 
Abstract

Proteomic analysis of exosomes (EX) poses a significant challenge. A 'gold-standard' method for plasma EX enrichment for downstream proteomic analysis is yet to be established. Our group has performed a comprehensive study of multi-dimensional enrichment methods to determine their efficiency for protein isolation. Methods were evaluated for their capacity to a) successfully isolate and enrich EX from blood plasma, b) minimise the presence of highly abundant plasma proteins, and c) result in the optimum representation of EX proteins by liquid chromatography tandem mass spectrometry (LC-MS/MS). Blood plasma from four animals (Bos taurus) of similar physical attributes and genetics were used. Three methods of EX enrichment were utilised: ultracentrifugation (UC), sizeexclusion chromatography (SEC), and ultrafiltration (UF). These enrichment methods were combined to create four groups for methodological evaluation: UC+SEC, UC+SEC+UF, SEC+UC and SEC+UF. $U C+S E C$ yielded the highest number of protein IDs. Plasma protein identification was the least in SEC+UC, but this method yielded the lowest number of protein IDs overall. UC+SEC+UF decreased EX protein ID and did not improve purity compared to UC+SEC. Our data suggest that the method and sequence of EX enrichment strategy impacts protein ID, which may influence the outcome of biomarker discovery studies.

Keywords: Exosome; isolation; enrichment; ultracentrifugation; size-exclusion chromatography; ultrafiltration; mass-spectrometry; proteomics; extracellular vesicles.

\section{Background}

The capability of instrumentation to analyse complex biological fluids and nanoparticles has advanced greatly in recent times. Advanced mass spectrometry (MS) and DNA sequencing platforms have become ubiquitous and accessible. Likewise, protocols for processing samples for downstream proteomics and genomics analyses have improved, which has had a positive impact on data quality and reproducibility (1,2). A subpopulation of extracellular vesicles (EVs), exosomes (EX), are nanoparticles of diameter $\sim 30-150 \mathrm{~nm}$ and have been the focus of many studies relating to biomarker development and targeted therapeutics (3-6). As integral cell-cell communicators and mediators of innumerable biological processes, typical exosomal cargo consists of nucleic acids, lipids and lipidmediators, and proteins $(5,7)$. Thus they continue to hold global interest for their diagnostic and therapeutic potential (8-10). However, their nano-size and complexity of cargo analysis continue to pose technical challenges. When derived from complex biological fluids such as plasma, multiple purification and enrichment steps are required, which invariably reduces overall particle yield $(10,11)$. Additionally, new evidence concerning the importance of EV subtypes, including exomeres ( $35-50$ $\mathrm{nm})$, microvesicles $(\sim 40-1000 \mathrm{~nm})$ and apoptotic vesicles $(\sim 100-1000 \mathrm{~nm})$ have further complicated the analyses of heterogenous or multivesicular samples $(12,13)$. While there are steady improvements in standardising enrichment protocols and improving particle purity and yield, there is no consensus for the best method of enrichment. This is likely due to the multitude of biological fluids from which EVs and EX can be isolated and enriched and the growing number of downstream applications now available to analyse the diverse exosomal cargo (14-16). The use of multi-omics approaches to EV and EX research is gaining popularity, giving way to a new wave of diagnostics. Recently, combined biomarker panels have been developed which consist of a number of protein and miRNA candidates and have been shown to improve sensitivity and specificity for pancreatic cancer screening (17).

Ultracentrifugation (UC) is one of the most widely used techniques for the enrichment of EVs from various types of biological fluids and cell culture media $(16,18)$. To increase purity of EV preparations, enrich for EX and decrease contaminant carryover, this is often followed or preceded by other 
enrichment or purification strategies, such as size-exclusion chromatography (SEC), or ultra-filtration (UF) $(16,18-20)$. The combination and order in which these enrichment processes are performed may influence the subpopulations of EVs obtained, the concentration, the particle sizes and/or purity of the final sample. It is unknown whether there is an optimal method and/or order of enrichment technique for specific downstream applications, such as MS-based proteomics (21-24). In this study we aim to determine the optimal enrichment method/s for protein analysis of EX isolated from blood plasma. Our approach utilised some of the most popular and widely accessible enrichment strategies to isolate and purify EX from biofluids; UC, SEC, and UF. It is important to clarify that while UC and SEC will enrich for EX, we have considered UF as an additional purification step to reduce contaminant carryover from blood plasma and concentrate particles. When referring to EV populations obtained from each method used in this study, the term 'EX' will be used to refer to all vesicles within the small EV size range (diameter $<200 \mathrm{~nm}$ ).

As targets for biomarker discovery, EX have been under investigation in agricultural studies for their ability to predict health status and reproductive outcomes in dairy cows (25-27). Our group has experience working with bovine blood plasma and therefore we have utilised samples from dairy cows for the purpose of this study.

\section{Material and Methods}

\section{Plasma collection}

Holstein-Friesian primiparous cows used in this study were part of a larger experiment performed by DairyNZ (Tokanui Farm, AgResearch), using an established model of dairy cow fertility as described by Meier et al (2017) (approved by the Ruakura Animal Ethics Committee AEC\#14200) (28). The use of all samples in this study was also approved by the Queensland University of Technology Animal Ethics Committee (QV reference \#83807 and \#83810). Criteria for inclusion were if calving occurred between week 28 and 31 (inclusive) (week = year week) $n=96$, which was between 9th July and 5th August 2017 (inclusive). Exclusion criteria were if a sample was missing (did not have both the milk and EDTA plasma samples), if there was no sample date recorded, or if the animal received a reproductive treatment. Additionally, cows were excluded if they had censored post-partum anestrous interval (PPAI) data (if PPAI sampling ended before PPAI was confirmed). From this larger group $(n=80)$, stored blood plasma samples of dairy cows $(n=4)$ of similar physical attributes, fertility status and genetics were used in this study (29). Animals were managed in a pasture-based, spring-calving dairy system. All experiments were performed in accordance with relevant guidelines and regulations. The authors confirm this study was carried out in compliance with ARRIVE guidelines (https://arriveguidelines.org/arrive-guidelines).

Blood samples for EX enrichment were collected as previously described by Crookenden et al (2018), with slight modification. Briefly, blood was collected by coccygeal venepuncture into evacuated blood tubes containing lithium heparin anticoagulant. Blood was immediately placed on ice and centrifuged at $1,500 \times \mathrm{g}$ for $12 \mathrm{~min}$ at $4^{\circ} \mathrm{C}$. The plasma was aspirated and stored at $-80^{\circ} \mathrm{C}$ until thawed for EX isolation. Two $10 \mathrm{~mL}$ aliquots of plasma per biological replicate were thawed on ice on the same day as EX isolation and enrichment was initiated. 


\section{EX isolation and enrichment}

\section{Pre-treatment}

Plasma samples of total volume $20 \mathrm{~mL}$ were centrifuged at $3,000 \times \mathrm{g}$ for $10 \mathrm{~min}$ at $4^{\circ} \mathrm{C}$ to remove debris, and the supernatant collected. The supernatant was then centrifuged at $12,000 \times \mathrm{g}$ for $30 \mathrm{~min}$ at $4^{\circ} \mathrm{C}$ to remove apoptotic cell bodies, and the supernatant collected. The supernatant was passed through a $0.22-\mu \mathrm{m}$ filter (Corning Costar), and two $500 \mu \mathrm{L}$ aliquots from each biological sample set aside and kept on ice for SEC. The remaining volume was split evenly for UC, a total of $8.5 \mathrm{~mL}$ per UC method (see Figure 1 for workflow). An aliquot of plasma ( $250 \mu \mathrm{L}$ ) was processed in the same way for use as a non-EX control in later proteomic analysis.

\section{Size-exclusion chromatography (SEC)}

$500 \mu \mathrm{L}$ of plasma from the previous step was passed through qEV original SEC columns (Izon, New Zealand) as per manufacturer's instructions. Briefly, the columns and filtered Dulbecco's Phosphate Buffered Saline (DPBS, pH 7.0 - 7.2) (Vitrolife, Australia) were brought to room temperature prior to loading the sample onto the column bed. The sample was loaded onto the column gel bed and $500 \mu \mathrm{L}$ fractions collected as follows; $1-6$ as void volume fraction ( $3 \mathrm{~mL}$ total), $7-10$ as exosomal (EX) fractions, and $11-16$ as non-exosomal (non-EX) fractions known to contain soluble plasma proteins, protein aggregates, and nucleic acids. One column was used per two animals to maintain group heterogeneity. In between uses, the columns were flushed with $0.5 \mathrm{~mL} 1 \mathrm{M} \mathrm{NaOH}$ solution, followed by $15-20 \mathrm{~mL}$ filtered DPBS.

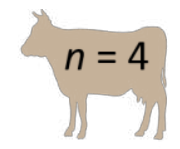

\section{Blood plasma processed for exosome enrichment}
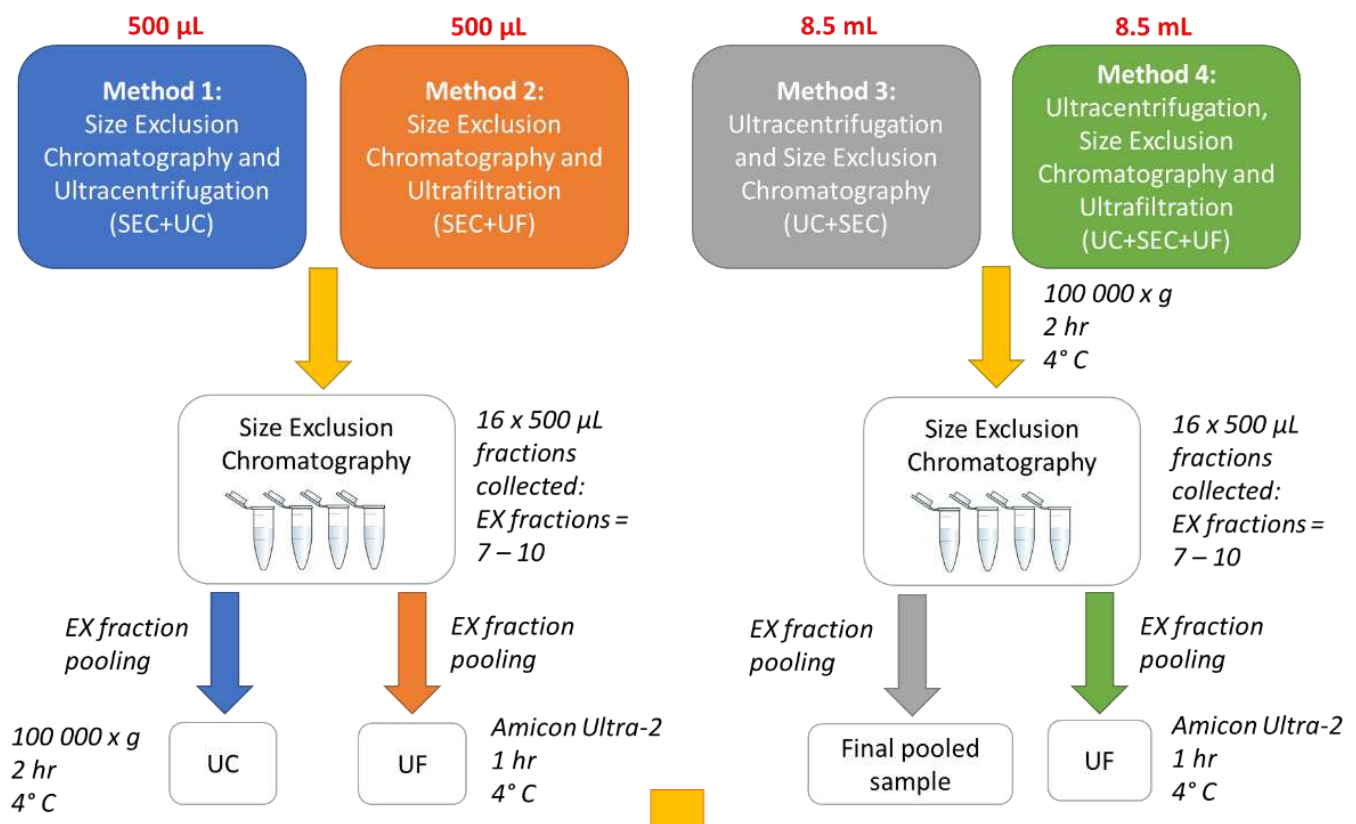

Analysis

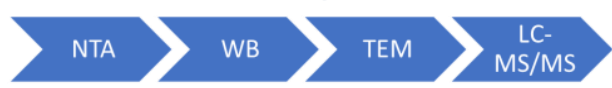

Figure 1. 
Ultrafiltration (UF)

$400 \mu \mathrm{L}$ of individual EX fractions resulting from SEC method described in [SEC] above were pooled to volume $1.6 \mathrm{~mL}$ and loaded onto pre-wetted Amicon Ultra-2 Centrifugal Filter Units with $3 \mathrm{kDa}$ cut-off (UFC200324, Merck Millipore). Samples were concentrated as per manufacturer's instructions for total time 80 minutes, to final volume $\sim 300 \mu \mathrm{L}$. Concentrate was collected by reverse centrifugation as per manufacturer's instructions. Concentrated samples were stored at $-80^{\circ} \mathrm{C}$ until further analysis.

Method 1: SEC + UC

SEC was performed as described in [SEC]. Following SEC, EX fractions $7-10$ for each sample were pooled to total volume $1.6 \mathrm{~mL}$, transferred to $8.9 \mathrm{~mL}$ OptiSeal Polypropylene Tubes (361623, Beckman Coulter) and brought to equal volume with DPBS. Samples were centrifuged at $100,000 \times g$ for $2 \mathrm{~h}$ at $4^{\circ} \mathrm{C}$ (Beckman, Type $70.1 \mathrm{Ti}$, Fixed angle ultracentrifuge rotor). The supernatant was discarded and pellet containing purified EVs resuspended in $500 \mu \mathrm{L}$ DPBS. Samples were stored at $-80^{\circ} \mathrm{C}$ until further analysis.

Method 2: SEC+UF

SEC and UF were performed consecutively as described in [SEC] and [UF]. The final concentrated pooled EX fraction 7-10 sample was stored at $-80^{\circ} \mathrm{C}$ until further analysis.

Method 3: UC+SEC

UC+SEC was performed as previously described (19): Briefly, cleared and filtered blood plasma supernatant of volume $8.5 \mathrm{~mL}$ was transferred into $32.4 \mathrm{~mL}$ OptiSeal Polypropylene Tube (361625, Beckman Coulter), and brought to equal volumes with DPBS. Samples were centrifuged at 100,000 $\times$ $g$ for $2 \mathrm{~h}$ at $4^{\circ} \mathrm{C}$ (Beckman, Type $50.2 \mathrm{Ti}$, Fixed angle ultracentrifuge rotor). The supernatant was discarded and the pellet containing EVs was resuspended in $500 \mu \mathrm{L}$ DPBS. Following ultracentrifugation (UC), samples were stored at $-80^{\circ} \mathrm{C}$ until the next day. Samples were thawed on ice to perform SEC. The $500 \mu \mathrm{L}$ EV sample was loaded onto SEC columns as described in [SEC]. EX fractions were pooled to final volume $1.6 \mathrm{~mL}$ and $50 \mu \mathrm{L}$ aliquoted immediately for micro bicinchoninic acid (BCA) assay. The remaining samples were stored at $4^{\circ} \mathrm{C}$ overnight prior to western blot analysis.

166 Samples for UC+SEC+UF were subjected to the same methods as described in [UC+SEC]. Final concentrated volumes were $\sim 100 \mu \mathrm{L}$. Concentrated samples were stored (in DPBS) at $4^{\circ} \mathrm{C}$ overnight prior to western blot analysis.

Sample pooling

UC+SEC individual fractions were pooled prior to NTA and MS analysis. All other methods were pooled prior to [UC] or [UF]. EX fractions 7, 8, 9 and 10 were pooled by equal volume to a total of $1.6 \mathrm{~mL}$. A small volume of individual EX fractions $(100 \mu \mathrm{L})$ was retained for analysis via NTA and western blot 173 (WB).

\section{Protein quantification}

The protein concentrations of pooled and/or concentrated samples resulting from the described methods $1-5$ were determined by micro BCA ${ }^{\mathrm{TM}}$ Protein Assay Kit (cat number 23235, Thermofisher Scientific, Australia) following the microplate assay protocol as per manufacturer's instructions. Briefly, bovine serum albumin (BSA) standards and EX samples (diluted 1:10) were solubilised 1:1 (v/v) in lysis buffer ( $1 \% \mathrm{w} / \mathrm{v}$ sodium deoxycholate (SDC) and $20 \mathrm{mM}$ Tris- $\mathrm{HCl} \mathrm{pH} \mathrm{8.5),} \mathrm{sonicated} \mathrm{in} \mathrm{an} \mathrm{ice}$ bath for $2 \mathrm{~min}$, heated at $95^{\circ} \mathrm{C}$ for $3 \mathrm{~min}$ and incubated on ice with gentle agitation for $20 \mathrm{~min}$ prior to 
assay. Protein standards were prepared in triplicate and samples in duplicate. $140 \mu \mathrm{L}$ of protein standard or sample/SDC lysis buffer was transferred onto a 96 well flat-bottom microplate (N2936, CELLSTAR, Greiner, Sigma) in triplicate (standard) or duplicate (sample). Micro BCA working reagent was added at a ratio of $1: 1$ with standard/sample and incubated at $37^{\circ} \mathrm{C}$ in the dark for $2 \mathrm{hrs}$, cooled to room temperature and absorbance read at $562 \mathrm{~nm}$.

\section{Western blot}

For visualisation of BSA in collected SEC fractions $1-16$, equal volumes $(10 \mu \mathrm{L})$ of sample from pooled SEC fractions 1-6, and individual SEC fractions $7-16$, were aliquoted for western blot analysis as previously described (19). Briefly, samples were transferred to an ice bath and sonicated for $2 \mathrm{~min}$. Samples were then placed on ice and 4x NuPAGE LDS sample buffer (NP0007, Thermofisher Scientific) and 10x NuPAGE sample reducing agent (NP0004, Thermofisher Scientific) were added to a final concentration of $1 \mathrm{x}$, and reduced for $10 \mathrm{~min}$ at $70^{\circ} \mathrm{C}$, as per manufacturer's instructions. For visualisation of Flotillin-1 (FLOT-1) in pooled EX $(7-10)$ and non-EX $(11-16)$ fractions, the same procedure was followed as for BSA, with slight modification. $2.5 \mu \mathrm{g}$ of total protein (methods UC+SEC, $U C+S E C+U F, S E C+U F$ ) or $2 \mu$ g of total protein $(S E C+U C$ ) was mixed with equal volume of $2 \%$ sodium dodecyl sulfate (SDS) in de-ionized $\mathrm{H}_{2} \mathrm{O}$, heated at $95{ }^{\circ} \mathrm{C}$ for 3 mins, and sonicated for 2 mins. Samples were dried in a vacuum concentrator (cat number 5305000380, Eppendorf Concentrator plus) and resuspended to final concentration $0.5 \mu \mathrm{g} / \mu \mathrm{L}$, with $5 \mathrm{uL}$ loaded per sample. Samples were resolved by electrophoresis on NuPAGE 4 to $12 \%$, Bis-Tris, $1.0 \mathrm{~mm}$, Mini Protein Gels, 15-well (NP0336BOX, Thermofisher Scientific) or 10-well (NP0321BOX, Thermofisher Scientific) with Chameleon ${ }^{\circledR}$ Duo Prestained Protein Ladder (928-60000, Li-COR, Australia). The protein gel was transferred onto a polyvinylidene fluoride membrane (Bio-Rad Laboratories Pty Ltd, Australia) using the Trans-Blot Turbo system. Membranes were briefly washed in phosphate buffered saline and 0.1\% Tween-20 (PBST), before blocking in $5 \mathrm{~mL}$ Odyssey Intercept blocking buffer (927-70001, Li-COR, Australia) and $5 \mathrm{~mL}$ phosphate buffered saline (PBS) for $1 \mathrm{hr}$ at RT. Antibody was diluted with 1:1 Odyssey Blocking buffer, PBS, and Tween-20 added to final concentration of $0.1 \%$. Samples were incubated with primary antibody overnight; anti-BSA (1:5000 dilution, Rabbit polyclonal, ab192603, Abcam, VIC); recombinant anti-Flotillin-1 (1:1000 dilution, Rabbit monoclonal, ab133497, Abcam, VIC) $(30,31)$. The next day, membranes were washed four times in PBST for $5 \mathrm{~min}$ each, and the membranes were incubated with secondary antibody for $1 \mathrm{hr}$ at RT in the dark with gentle rocking; Goat anti-Rabbit IgG (1: 15000 dilution, Li-COR, Australia). Antibody was diluted with 1:1 Odyssey Intercept blocking buffer, PBS, and Tween-20 added to final concentration of $0.1 \%$. The membranes were washed in PBST four times for 5 min each. Membranes were rinsed briefly in PBS and imaged with Li-COR Odyssey fluorescent scanner at 700 and $800 \mathrm{~nm}$. All images were processed using Image Studio Lite v5.2. Contrast and brightness were adjusted equally across entire images to best visualise protein bands.

\section{Nanoparticle tracking analysis (NTA)}

NTA measurements were performed using a NanoSight NS500 instrument (NanoSight NTA 3.1 Build 3.1.46). Instrumentation calibration was performed using $100 \mathrm{~nm}$ synthetic beads at a 1:250 dilution. Measurements of samples included particle concentrations, mean and mode sizes of nanoparticles enriched from blood plasma in individual SEC fractions generated from the SEC+UC method prior to $U C$, and UC+SEC group post SEC. SEC+UC pooled samples and UC+SEC pooled samples were analysed separately. NTA data were compiled into one .xls file before being transferred and analysed in GraphPad Prism (v9.1.2).

\section{Transmission electron microscopy (TEM)}

Imaging of samples by TEM was outsourced and performed by the Central Analytical Research Facility microscopy laboratory, Queensland University of Technology (Brisbane, Australia). All biological 
replicates were imaged for each method of EX isolation and enrichment for pooled samples. A representative biological replicate was chosen for individual fraction analysis for UC+SEC vs SEC. Samples were drop mounted onto formvar coated 200mesh Cu grids for $1 \mathrm{~min}$, excess wicked away and negatively stained with $2 \%$ UA for 3 min. Excess was wicked away with filter paper and left to air dry. If dilution was required, samples were remounted as previous, at a $50 \%$ dilution in milliQ water. Samples were imaged on a JEOL JEM-1400 TEM operated at $100 \mathrm{kV}$, mounted with a $2 \mathrm{~K}$ TVIPS CCD camera.

\section{Protein digestion}

Pooled 7-10 fractions and were combined for each method to create a master pool per method and processed for MS analysis using a modified filter aided sample preparation (FASP) (1). For the master pool EX samples, a volume of protein extract corresponding to $10-20 \mu \mathrm{g}$ total protein was mixed at

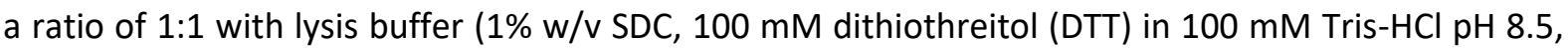
cOmplete-mini EDTA-free protease inhibitor cocktail (Roche)). For the plasma control sample, a volume of plasma corresponding to $\sim 10-20 \mu \mathrm{g}$ total protein was mixed with $19 \mu \mathrm{L}$ lysis buffer (total volume $20 \mu \mathrm{L}$ ) as described for EX samples. All samples were sonicated in an ice bath for $2 \mathrm{~min}$ and incubated on ice for $20 \mathrm{~min}$. Samples were loaded onto Nanosep ${ }^{\circledR}$ Centrifugal Devices with Omega ${ }^{\mathrm{TM}}$ Membrane $30 \mathrm{~K}$ (PALL) and centrifuged at $14,000 \times \mathrm{g}$ for $15 \mathrm{~min}$ at $21^{\circ} \mathrm{C}$. As EX sample volumes exceeded device capacity, EX samples were loaded onto device in $450 \mu \mathrm{L}$ aliquots and centrifuged as described. This was repeated until all the sample had passed through the filter. Flow-through was stored at $-80^{\circ} \mathrm{C}$ for quality control analysis by SDS-PAGE to observe occurrence and relative amount of protein loss. In all other cases, flow-through was discarded. Proteins bound to the filter membrane were reduced with $200 \mu \mathrm{L}$ of DTT-Urea buffer (8M urea, $100 \mathrm{mM}$ Tris-HCl pH 8.5, $25 \mathrm{mM}$ DTT) for 60 $\mathrm{min}$ at RT will gentle agitation. Samples were centrifuged at $14,000 \times \mathrm{g}$ for $15 \mathrm{~min}$ at $21^{\circ} \mathrm{C}$. Filters were washed with $200 \mu \mathrm{L}$ Urea-Tris buffer ( $8 \mathrm{M}$ urea, $100 \mathrm{mM}$ Tris-HCl pH 8.5) and centrifuged at 14,000 x $g$ for $15 \mathrm{~min}$ at $21^{\circ} \mathrm{C}$. Reduced samples were alkylated with $100 \mu \mathrm{L}$ IAM-Urea buffer $(50 \mathrm{mM}$ iodoacetamide (IAM), $8 \mathrm{M}$ Urea-Tris buffer) and incubated at RT for $20 \mathrm{~min}$ on agitator. The filters were centrifuged at $14,000 \times \mathrm{g}$ for $15 \mathrm{~min}$ at $21^{\circ} \mathrm{C}$. The filters were washed twice with $200 \mu \mathrm{L}$ UreaTris buffer and centrifuged at $14,000 \times g$ for $15 \mathrm{~min}$ at $21^{\circ} \mathrm{C}$ each. The filters were equilibrated with two washes, $200 \mu \mathrm{L} 100 \mathrm{mM}$ ammonium bicarbonate (AMBIC) and centrifugation at 14,000 $\mathrm{xg}$ for 15 min at $21^{\circ} \mathrm{C}$. Samples were digested overnight ( $16 \mathrm{~h}$ ) with trypsin (Trypsin Gold, Mass Spectrometry Grade, Promega) at $37^{\circ} \mathrm{C}$ in a humidified chamber with gentle agitation, with volume of trypsin added at an enzyme to protein ratio of 1:50. The next day, filters were transferred to clean $1.5 \mathrm{~mL}$ Eppendorf tubes and peptides collected by centrifugation at $14,000 \times \mathrm{g}$ for $15 \mathrm{~min}$ at $21^{\circ} \mathrm{C}$. One additional elution was performed by adding $20 \mu \mathrm{L} 100 \mathrm{mM}$ AMBIC and centrifugation at $14,000 \times \mathrm{g}$ for $15 \mathrm{~min}$ at $21^{\circ} \mathrm{C}$.

\section{Peptide desalting}

Peptide digests were acidified by mixing 1:1 with $4 \%$ trifluoroacetic acid (TFA) solution. StageTips were produced with double SCX membrane (part no: 2251, Empore) as described in Supplementary file 2. $30 \mu \mathrm{L} 100 \%$ acetonitrile (ACN) was passed through the tip using centrifugal force ( 2 min spin at 2,000 $\mathrm{rpm}$ ) and positive pressure. $30 \mu \mathrm{L}$ of $5 \%$ ammonium hydroxide/80\% ACN (Buffer DE) was added to the tips and passed through the tip using centrifugal force and positive pressure. $30 \mu \mathrm{L}$ of $0.2 \%$ TFA (Buffer DW) was added to the tip and passed through the tip using centrifugal force and positive pressure. Each sample was loaded onto a StageTip and passed through the tip using centrifugal force and positive pressure. $30 \mu \mathrm{L}$ of DW was added to the tip and passed through the tip using centrifugal force or positive pressure, three times in total. The tip was placed in a clean $1.5 \mathrm{~mL}$ tube and $30 \mu \mathrm{LE}$ was added to the tip and passed through the tip using centrifugal force or positive pressure. The eluted peptides were dried in a vacuum centrifuge and reconstituted in $20 \mu \mathrm{L}$ iRT buffer (Biognosys-11). 
274 Samples were assayed for peptide concentration with Pierce ${ }^{\mathrm{TM}}$ Quantitative Colorimetric Peptide Assay according to manufacturer's instructions (cat number 23275, Thermofisher Scientific). Peptide concentration in all samples were equalized by an appropriate addition of iRT buffer.

All peptide samples were analysed by LC-MS/MS as follows. Reversed-phase chromatography was conducted on an Eksigent ekspert nanoLC 400 System (Eksigent Technologies) using trapping for $3 \mathrm{~min}$ at flow rate of $10 \mu \mathrm{L} / \mathrm{min}$ onto a Trajan ProteCol trap $(120 \AA, 3 \mu \mathrm{m}, 10 \mathrm{~mm} \times 300 \mu \mathrm{m})$ followed by separation on an Eksigent ChromXP C18 $3 \mu \mathrm{m} 120 \AA$ (3C18-CL-120, $3 \mu \mathrm{m}, 120 \AA$, $0.3 \times 150 \mathrm{~mm}$ ) analytical column at a flow rate of $5 \mu \mathrm{L} / \mathrm{min}$ maintained at $40^{\circ} \mathrm{C}$. Trapping utilized mobile phase A only whereas separation utilised a combination of mobile phase $A$ and $B$. Mobile phase A consisted of $0.1 \%$ FA in water and mobile phase B was made of $0.1 \%$ FA in ACN. Peptides were separated by 68 min linear gradient of 3-25\% mobile phase B followed by 5 min linear gradient of $25-35 \%$ mobile phase $B$. After peptide elution, the column was flushed with $80 \%$ mobile phase B for 5 min and re-equilibrated with $97 \%$ A for 8 min before next injection. Mass spectrometry was conducted on Triple time-of-flight (TOF) 6600 (SCIEX) instrument equipped with DuoSpray Ion Source configured for micro flow HPLC applications.

\section{DDA-MS data acquisition}

High resolution $(30,000)$ TOF MS scan was collected over range of $m / z 400-1250$ for $0.25 \mathrm{~s}$, followed by high sensitivity TOF MS/MS scans over a range of $\mathrm{m} / z 100-1800$ on up to the 30 most abundant peptide ions ( $0.05 \mathrm{~s}$ per each scan) that had intensity greater than $150 \mathrm{cps}$ and charge state of 2-5. The dynamic exclusion duration was set at $15 \mathrm{~s}$. Ion fragmentation in the collision cell used rolling collision energy with the collision energy spread set to $5 \mathrm{eV}$. The declustering potential was set to 80 $\checkmark$ and the remaining gas and source parameters were adjusted as required.

\section{Protein identification}

MS data files were added to ProteinPilot (v. 5.0.2.0, 5346) and processed individually, using Paragon Algorithm (v. 5.0.2.0, 5174). The fragmentation spectra were searched against cattle proteome (23,847 sequences, downloaded Aug 2020, available in fasta format, Uniprot), combined with sequences of cRAP (ftp://ftp.thegpm.org/fasta/cRAP) and iRT peptides. The following search parameters were entered: Urea denaturation; alkylation with iodoacetamide; species 'none'; amino acid substitution; thorough ID; false discovery rate (FDR) analysis 0.01 . The protein list was exported to a .xls file, which was subject to an additional refinement. The final list of proteins for each method required minimum 2 peptides per protein ID (1\% FDR at the protein level; 5\% FDR at the peptide level). All EX samples were compared to a plasma control sample analysed in the same way.

\section{Gene ontology analysis}

Proteins identified in ProteinPilot as described above were analysed for gene ontology (PANTHERGO, Gene Ontology Phylogenetic Annotation Project, $v$ 16.0. Available online: http://www.pantherdb.org/), including molecular function, cellular component, biological process, pathway analysis, and protein class. Protein accession codes were entered into the search window and searched against species Bos taurus and analysed for functional classification. FunRich (Functional Enrichment analysis tool) was used to perform enrichment analysis on proteins identified from each enrichment method as compared to the plasma control sample. The complete Vesiclepedia database (version 4.1, downloaded on 27/07/2021, available at http:// microvesicles.org/Archive/VESICLEPEDIA PROTEIN MRNA DETAILS 4.1.txt) was imported into FunRich and all data were searched against the cattle proteome. 
NTA data were analysed using GraphPad Prism v9.1.2. Mean and mode size of pooled EX fractions 710 in UC+SEC and SEC+UC methods were compared using a paired student's t-test (two-tailed) and significance set to $p<0.05$. The same analysis was performed for particle concentration between $U C+S E C$ and SEC+UC methods. Data were also assessed for normality of residuals and all data passed normality testing (Shapiro-Wilk, alpha $=0.05$ ).

324

325

326

327

328

329

330

331

332

333

334

335

336

337

338

339

340

341

342

343

344

345

346

347

348

\section{Results}

\section{Western blot}

Serum albumin, and in the case of this study BSA, is a highly abundant plasma protein. Optimal identification of EX proteins depends upon efficient depletion of BSA from EX enriched samples prior to MS analysis. WB analysis was performed on individual fractions from UC+SEC and SEC prior to $U F / U C$ to determine the relative abundance of BSA in these samples. Blots were probed with anti-BSA antibody to determine the BSA elution profile and the relative abundance of BSA in EX fractions 7 10. SEC alone resulted in low BSA signal in EX fractions 7-9, with an increase in intensity observed in EX fraction 10, and significant increase from non-EX fraction 11 onwards (Figure 2, top). In the case of $U C+S E C$ there was a stronger BSA signal in EX fraction 7 as compared to EX fractions 8-10, with signal increasing from non-EX fraction 12 onwards (Figure 2, bottom).

As the presence of EX marker FLOT-1 can vary depending on enrichment strategy and the biofluid being analysed, it was of interest to determine whether it could be identified following the enrichment methods used in this study $(13,32)$. FLOT-1 was not identified in any of the pooled EX and non-EX fractions (Figure 3A-C). As human placental homogenates are positive for FLOT-1 expression, the human placental choriocarcinoma cell line JEG-3 was used as a positive control (33).

\section{$\begin{array}{lllllllllllllll}\mathrm{L} & \mathrm{B} & \mathrm{C} & \mathrm{B} & 7 & 8 & 9 & 10 & 11 & 12 & 13 & 14 & 15 & 16 & 1-6\end{array}$}

A

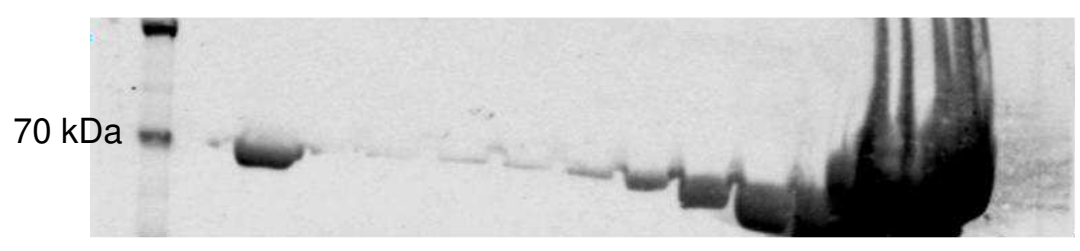

B

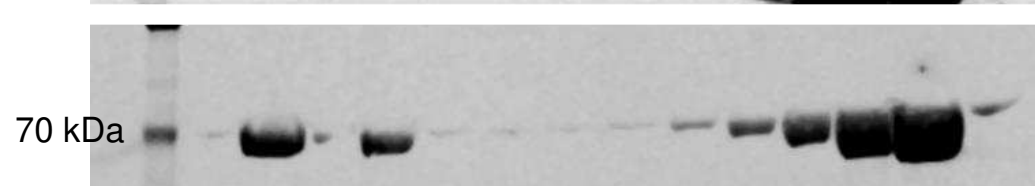

\section{Figure 2.}


352

353

354

355

356

357

358

359

360

361

362

363

364

365

366

367

368

369

370

371

372

373

374

375

376

377

378

379

380

381

382

383

384
A

$50 \mathrm{kDa}$

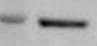

B

$50 \mathrm{kDa}$

\section{UC+SEC+UF}

+ve -ve SEC+UF

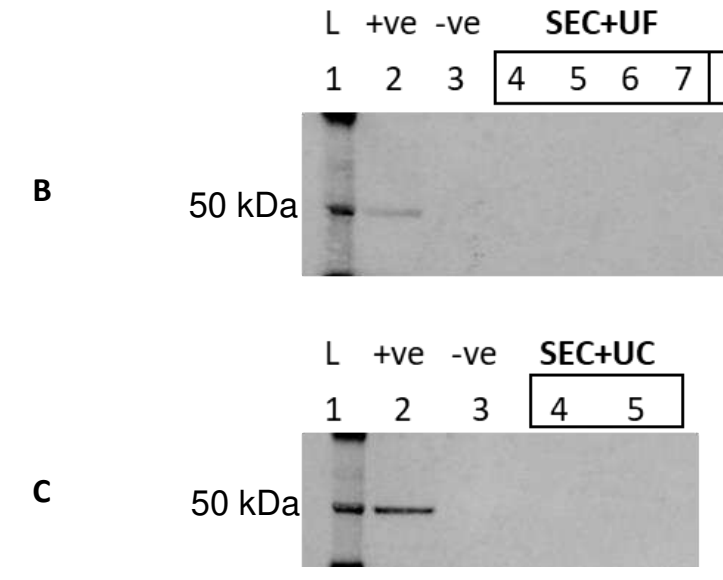

Figure $3 A-C$.

\section{NTA}

\section{Particle concentration profiles and protein yield.}

To determine whether performing UC prior to SEC results in similar particle concentration profiles, the particle concentrations obtained by SEC and UC+SEC in fractions $1-16$ were compared using NTA. The overlaid profiles (Figure 4A) demonstrate particles produced by SEC are concentrated in EX fractions 8 and 10, and non-EX fraction 13. UC+SEC resulted in an earlier peak particle elution in EX fraction 7 and further peaks in non-EX fractions 12, 13 and 15.

Multiple EX enrichment steps can lead to a significant reduction in particle yield. Total particle yield was determined to differentiate whether one method is optimal for particle recovery per $\mathrm{mL}$ of blood plasma processed. Pooled fraction analysis of SEC+UC Vs UC+SEC showed a significant increase in particle concentration in the UC+SEC method (Supplementary figure S8A). Overall particle yield was higher by UC+SEC method (Supplementary figure S8B), as was expected due to the difference in starting volume of plasma used for each enrichment method. However, when normalised to $\mathrm{mL}$ of starting material, no differences in yield were observed between these methods, although variability was greater by SEC+UC method (Supplementary figure S8C). Purity estimates of UC+SEC and SEC+UC were determined by calculating the number of particles in EX fractions 7-10 per $\mu \mathrm{g}$ of protein, as determined by micro BCA assay (Supplementary figure S9A). UC+SEC contained more particles/ug protein than $S E C+U C$, although this was not statistically significant. UC+SEC was also less variable than $\mathrm{SEC}+\mathrm{UC}$ in this respect. 
401

402

403

404

405

406

407

408

409

410

411

412

413

414

415

416

417

418

419

420

421

422

423

424

425

426

427

Size distribution profiles.

The order in which enrichment methods are performed may affect the size distribution of the EX population obtained, potentially introducing bias towards an EX subpopulation of a specific size range. To observe the effect that the order of enrichment method has on particle size distribution, the mean and mode size ranges for particles produced by SEC, SEC+UC and UC+SEC are shown in Figure 4B. These methods enriched for particles contained in EX fractions 7-10 that fell within the small EV (diameter $<200 \mathrm{~nm}$ ) range. Mean sizes of individual EX fractions produced by SEC were of diameter $\sim 150 \mathrm{~nm}$ (Figure 4B), whereas those produced by UC+SEC were of diameter $175-190 \mathrm{~nm}$. Similarly, mode sizes of particles in SEC EX fractions ranged from diameter $\sim 96-110 \mathrm{~nm}$, whereas UC+SEC EX fractions produced particles with mode sizes of diameter $\sim 116-167 \mathrm{~nm}$. Pooled EX fraction analysis (Figure 4C) was consistent with this size difference, with the SEC+UC 7-10 pool enriching for particles of mode size $\sim 107-120 \mathrm{~nm}$, and UC+SEC $7-10$ pool enriching for particles of mode size $130-135$ $\mathrm{nm}(p<0.05)$. Similarly, mean particle sizes of SEC and UC+SEC $7-10$ pooled EX were $150-174 \mathrm{~nm}$ and $166-182 \mathrm{~nm}$, respectively $(p<0.05)$.

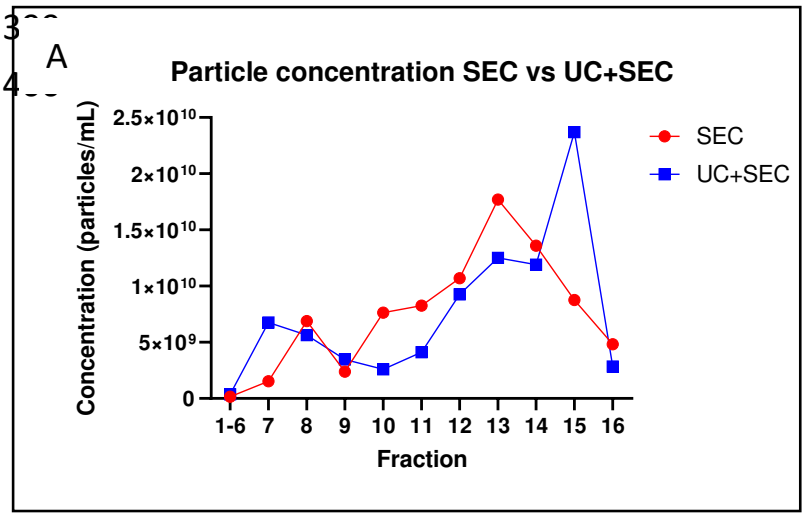

B Mean size SEC vs UC+SEC

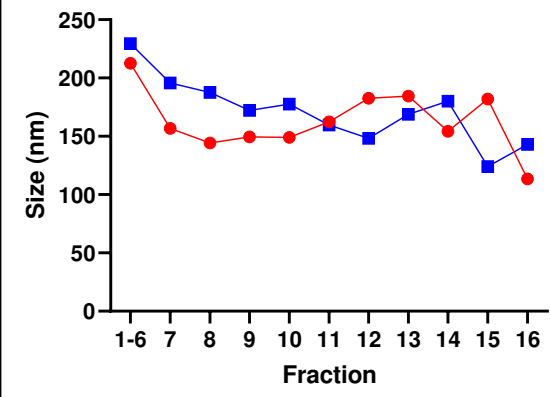

$\bullet$ SEC

- UC+SEC

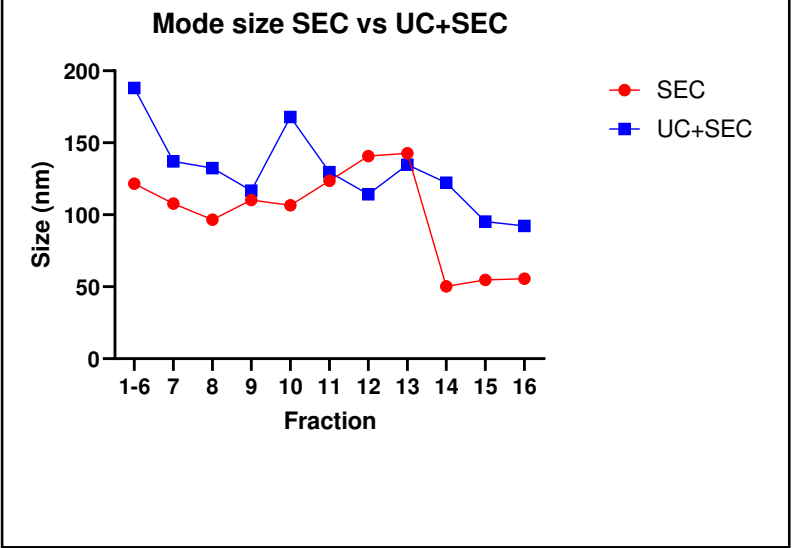

C

Mean size SEC+UC vs UC+SEC F7-10 pools

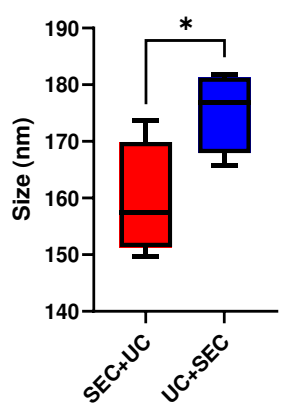

Mode size SEC+UC vs UC+SEC F7-10 pools

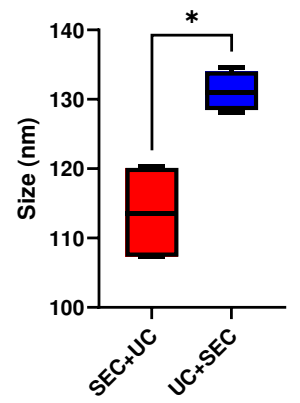

Figure 4. 
TEM

EX particles were visualised in pooled fractions $7-10$ from each method. EX ranged from $50-150$ $\mathrm{nm}$ and were distinguishable by their distinct cup- or round-shaped morphology (see Figure 5B) (34). SEC+UC contained smaller particles compared to that identified in all other methods. Wide-view images visualised numerous large $(>150 \mathrm{~nm})$ particles in UC+SEC+UF and SEC+UF, whereas UC+SEC and SEC+UC methods showed particles in the smaller size range $(<150 \mathrm{~nm})$ (Figure $5 A)$. EX particles were not visualised in non-EX fractions $11-16$ (Representative non-EX TEM images are available in Supplementary Figures S6-7).

\section{A}
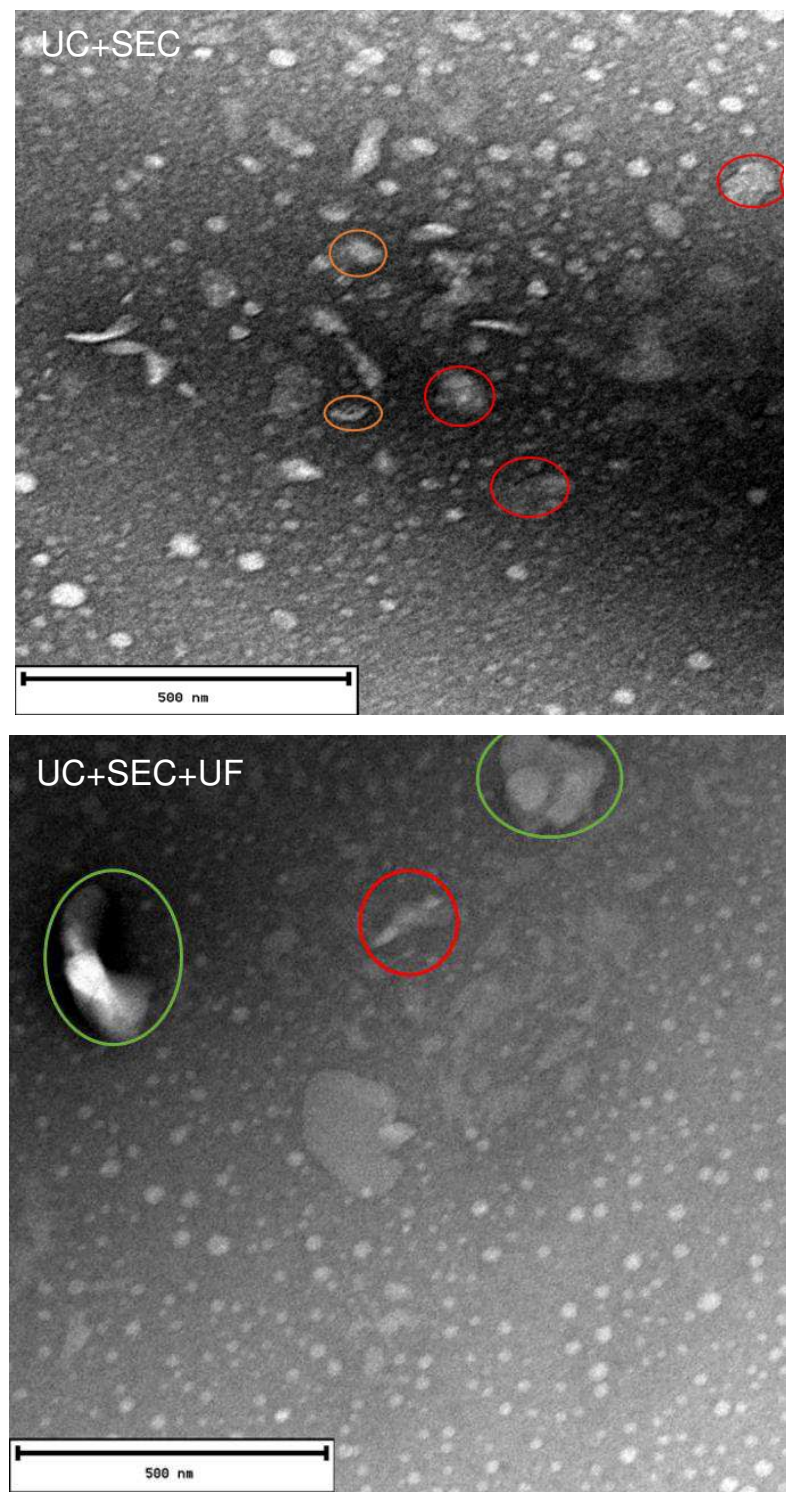
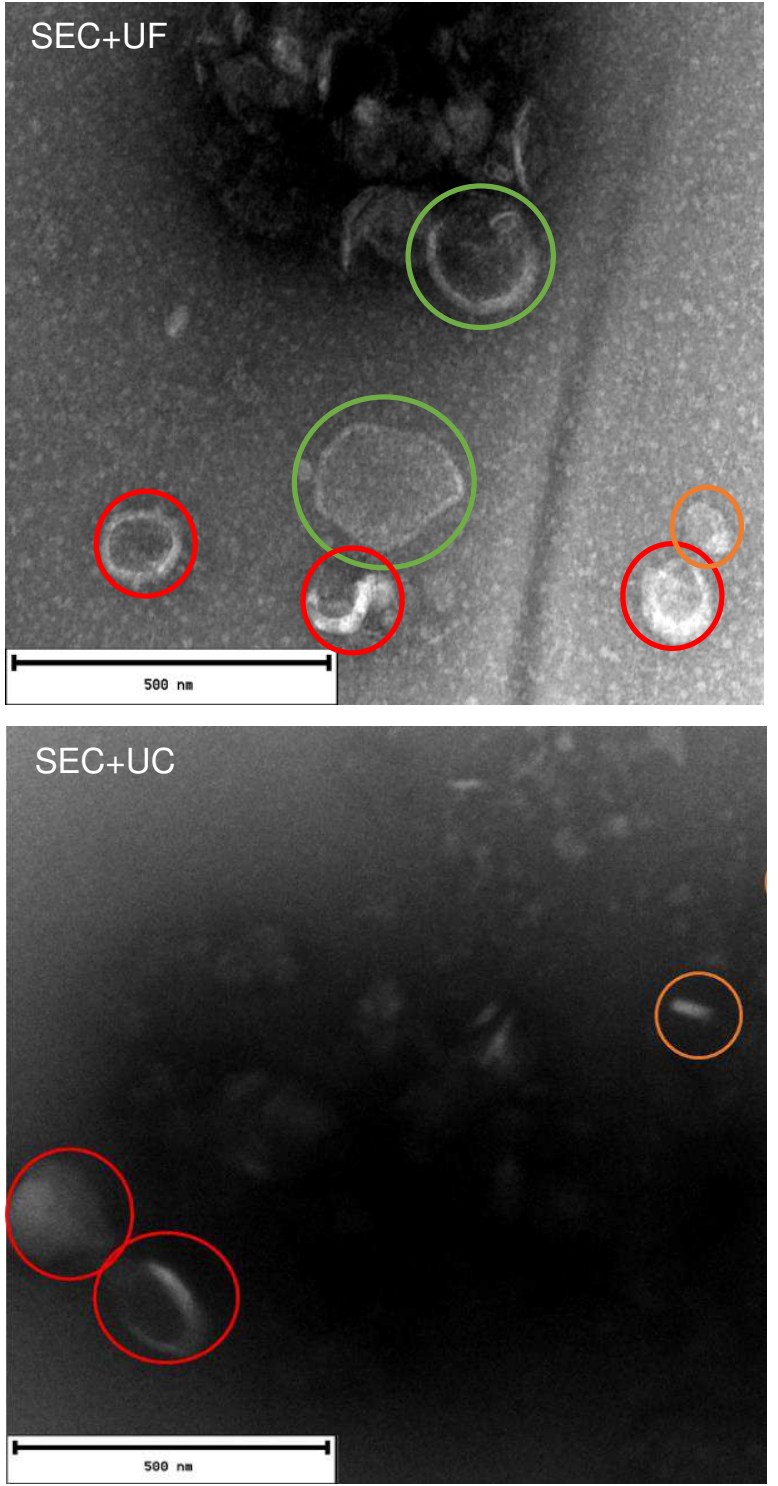


\section{Figure $5 A$ and $B$.}

MS

\section{Total protein quantification}

480 Micro BCA assay was used to determine the total protein yield in samples enriched for EX prior to MS sample preparation. SEC+UF produced samples with the highest concentration of protein $(\sim 40-150$ $\mu \mathrm{g} / \mathrm{mL}$ ) but was the most variable (Supplementary figure S9B). All other methods produced protein yields of $<40 \mu \mathrm{g} / \mathrm{mL}$. Protein determination was used to calculate the volumes of samples required for protein digestion prior to MS analysis.

UC+SEC enrichment method results in the highest number of protein IDs.

The proteomic content of EVs and EX are of paramount importance in biomarker studies. Therefore, the effect that the various enrichment methods in this study have on overall EX protein ID, the level of contamination with non-EX proteins from each enrichment method, and the consistency of results with online databases of known EX proteins were determined by MS analysis in DDA acquisition mode. The total number of protein IDs at $1 \%$ FDR is shown in Table 1. Protein IDs were processed further to include 5\% FDR analysis at the peptide level, and minimum 2 peptides per protein. Venn diagram illustrates shared proteins amongst the various enrichment methods and plasma control (Figure 6). 
Table 1.

\begin{tabular}{|l|l|l|l|l|l|l|l|l|}
\hline Method & \multicolumn{2}{|c|}{ UC+SEC } & \multicolumn{2}{c|}{ UC+SEC+UF } & \multicolumn{2}{c|}{ SEC+UF } & \multicolumn{2}{c|}{ SEC+UC } \\
\hline $\begin{array}{l}\text { FDR } \\
\text { method }\end{array}$ & $1 \%$ FDR & $\begin{array}{l}5 \% \text { FDR, 2 } \\
\text { pep }\end{array}$ & $1 \%$ FDR & $\begin{array}{l}5 \% \text { FDR, 2 } \\
\text { pep }\end{array}$ & $1 \%$ FDR & $\begin{array}{l}5 \% \text { FDR, 2 } \\
\text { pep }\end{array}$ & $1 \%$ FDR & $\begin{array}{l}5 \% \text { FDR, 2 } \\
\text { pep }\end{array}$ \\
\hline $\begin{array}{l}\text { Number } \\
\text { of } \\
\text { proteins } \\
\text { identified }\end{array}$ & $\mathbf{3 4 9}$ & 247 & 237 & 155 & 251 & 128 & 81 & 49 \\
\hline
\end{tabular}

497

498

499

500

501

502

503

504

505

506

507

508

509

510

511

Figure 6.

512

513 UC+SEC resulted in the highest number of identified proteins (see Figure 6). Of the top $100 \mathrm{EV}$ proteins 514 in online databases ExoCarta and Vesiclepedia, UC+SEC enabled identification of the most in both 515 instances (28 and 31, respectively). While SEC+UF had the third highest number of protein IDs, only 8 516 and $6 \mathrm{EV}$ proteins were identified from ExoCarta and Vesiclepedia, respectively. Figure 7 displays the 517 percentage of the total number of proteins identified in the top $100 \mathrm{EV}$ protein list by all EX enrichment 518 methods. The complete list of proteins can be found in Supplementary file 2 (Tables S1 and S2). Only 519 one EX protein was identified in all enrichment methods and not in the plasma control group: Galectin5203 binding protein (LGALS3BP). The tetraspanin CD9 was present in the UC+SEC, UC+SEC+UF, and 521 SEC+UF methods, and absent from SEC+UC method. CD81 was present in UC+SEC and UC+SEC+UF 522 methods and absent in SEC+UC and SEC+UF. Of notable absence from all EX enrichment methods were 523 EX markers tumour susceptibility gene 101 (TSG101) and flotillin-1 (FLOT-1). UC+SEC also resulted in 524 the best sequence coverage (\%, 95 confidence) for each protein ID in the top $100 \mathrm{EV}$ list, where the protein was identified by more than one method (see Supplementary file 1). 
Figure 7.

Proteomic comparison of UC+SEC with the complete Vesiclepedia protein database identified 138 proteins in UC+SEC that were annotated in Vesiclepedia, while 21 were uniquely identified in this EX enrichment method (Supplementary Figure S10A). Gene ontology analysis of these 21 unique proteins in PantherGO identified gene families associated with vesicle-mediated transport (GO:0006897; GO:0009987; GO:0006900), plasma membrane (GO:0005886), and cell-cell recognition (GO:0008037; GO:0009987) (see Supplementary files 3 and 4 for PANTHERGO gene ontology terms). UC+SEC+UF method shared 12 of the 21 unique proteins identified in the UC+SEC method, including those associated with vesicle-mediated transport and cell communication (GO:0006897; GO:0009987; GO:0006900).

To assess the total number of known EV proteins resulting from each enrichment method, only mapped proteins were compared to the Vesiclepedia database and plasma control. UC+SEC resulted in the highest number of EV proteins annotated in the Vesiclepedia database, but also identified the highest number of plasma proteins (Figure 8). All methods resulted in identification of $51-55$ plasma 


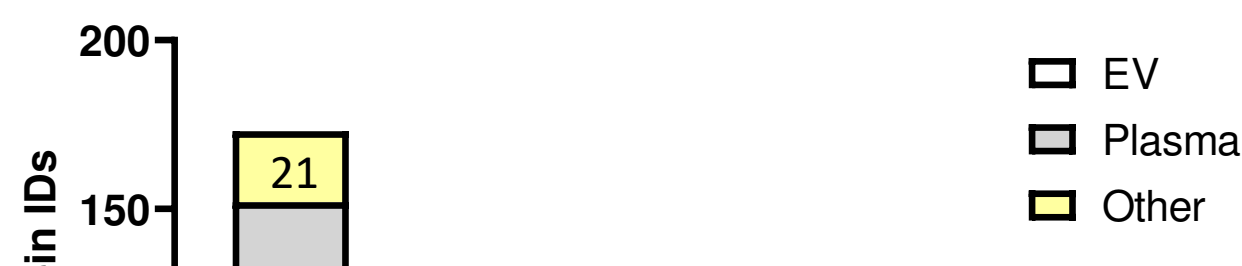

Figure 8.

EX have been implicated in numerous signalling pathways related to the pathogenesis of disease and cancer metastasis. Therefore, EX isolation and enrichment methods were also assessed for the enrichment of proteins involved in pathways known to be associated with EX (Supplementary file 2 Table S4). Proteins associated with Cadherin, p53, Wnt, Alzheimer disease-presenilin pathway and CCKR map signalling pathways were increased compared to the plasma control in all methods except for SEC+UC. Proteins associated with the Integrin signalling pathway were enriched in all methods compared to plasma, while proteins in the Huntington's Disease pathway were enriched in UC+SEC and SEC+UF methods only. UC+SEC+UF provided the best enrichment of proteins in the Cadherin, Wnt, CCKR, Alzheimer's, and p53 pathways.

Depletion of abundant plasma proteins following EX enrichment.

Optimal MS data acquisition for EX enriched samples relies on the successful depletion of highly abundant plasma proteins, which may overshadow the detection of less abundant EX proteins. As EX proteins are often associated with the plasma membrane (PM) and the internal environment of the cell, functional enrichment analysis for proteins associated with the PM and cytoplasm was performed using the online software tool FunRich. Proteins detected in each method of enrichment and a plasma control were compared with respect to cellular component (see Figure 9). SEC+UC enriched for proteins associated with the PM but were depleted/not present in all other categories. UC+SEC resulted in a 2.5 -fold increase in proteins associated with the $P M$, integral component of membrane and cytoplasm than the plasma control. UC+SEC, UC+SEC+UF and SEC+UF methods did not significantly alter the number of proteins associated with the external side of the plasma membrane, although UC+SEC+UF outperformed the other methods in this case. 


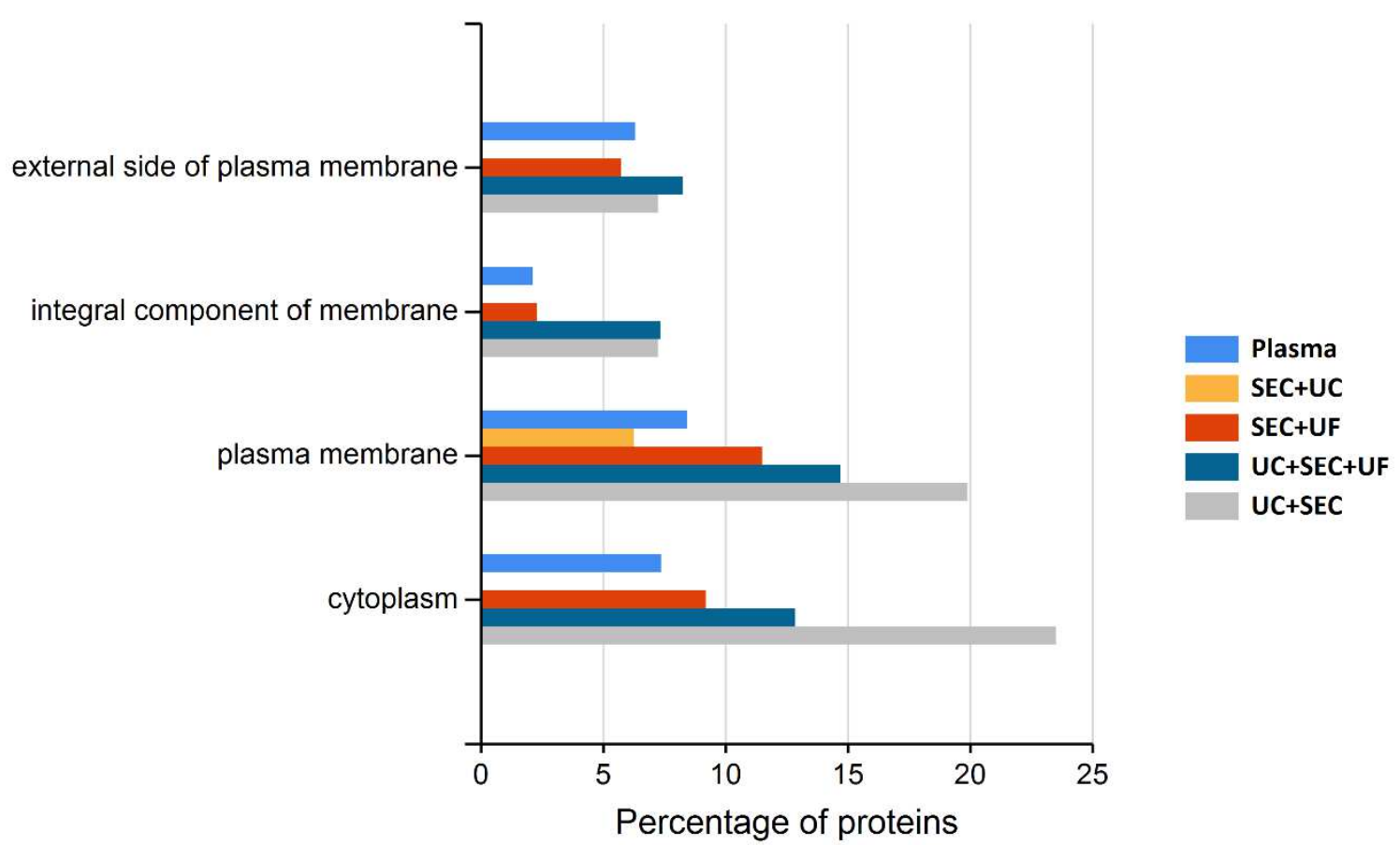

Figure 9.

To further explore the level of blood plasma components in EX samples derived from each method of enrichment, gene ontology for pathway analysis was carried out using PANTHERGO. Pathway analysis revealed that $44 \%$ of proteins identified in the SEC+UC method were associated with blood coagulation, compared with $24 \%$ in UC+SEC, $29 \%$ SEC+UF, $21 \%$ UC+SEC+UF, and $39 \%$ plasma control (Supplementary file 2 Table S4).

Finally, each EX isolation and enrichment method was assessed for its efficacy in depleting abundant plasma proteins via peptide ID analysis. EX enriched samples were assessed by comparing the number of peptides identified for known abundant plasma proteins to a blood plasma control sample (35). The proportion of peptides in EX enrichment methods versus plasma control peptides was calculated for each plasma protein (see Table 2). All methods resulted in increased peptide ID for IgA/IgM, while only those methods utilising UC first showed a $3-3.67$-fold increase in peptide ID for haptoglobin as compared to the plasma control. SEC+UF increased peptide ID of low-density lipoprotein (LDL), whereas all other methods showed fewer LDL peptide IDs. The depletion of albumin peptides was greatest in the UC+SEC and UC+SEC+UF methods. 
Table 2.

\begin{tabular}{|l|r|r|r|r|}
\hline Plasma Proteins & \multicolumn{1}{|c|}{ UC+SEC } & UC+SEC+UF & \multicolumn{1}{l|}{ SEC+UF } & \multicolumn{1}{c|}{ SEC+UC } \\
\hline Albumin & 0.16 & 0.16 & 0.31 & 0.24 \\
\hline a1-Antitrypsin & 0.31 & 0.19 & 0.38 & 0.08 \\
\hline IgA/IgM & 6.25 & 6.25 & 5.75 & 1.50 \\
\hline Transferrin & 0.00 & 0.19 & 0.00 & 0.00 \\
\hline Haptoglobin & 3.33 & 3.67 & 0.00 & 0.00 \\
\hline a2-Macroglobulin & 1.22 & 0.84 & 1.49 & 0.18 \\
\hline Fibrinogen & 1.86 & 1.41 & 3.24 & 0.35 \\
\hline Complement C3 & 0.48 & 0.37 & 0.51 & 0.09 \\
\hline a1-Acid Glycoprotein (Orosomucoid) & 0.00 & 0.00 & 0.00 & 0.00 \\
\hline HDL (Apolipoproteins A-I) & 0.55 & 0.45 & 0.73 & 0.27 \\
\hline HDL (Apolipoproteins A-II) & 0.50 & 0.50 & 0.50 & 0.00 \\
\hline LDL (mainly Apolipoprotein B) & 0.29 & 0.13 & 1.95 & 0.00 \\
\hline Hemoglobin subunit alpha & 0.88 & 0.75 & 0.00 & 0.00 \\
\hline Hemoglobin subunit beta & 1.07 & 0.86 & 0.64 & 0.14 \\
\hline
\end{tabular}

We have demonstrated that EX enrichment from blood plasma for the purpose of downstream proteomics can be achieved by UC, SEC and UF performed in various combinations and orders. The optimal enrichment strategies were determined by the characterisation of EX (NTA, WB, TEM, particle yield), purity (particles/ $\mu$ g protein and semi-quantitation of abundant blood plasma proteins), number of protein IDs, and the top 100 number of EV markers (ExoCarta and Vesiclepedia) identified in each method of enrichment. SEC, SEC+UC and UC+SEC were all successful in enriching for particles in the EX size range in EX fractions 7-10. UC+SEC resulted in the greatest number of identified EV markers while also reducing the number of peptide IDs in 9 out of 14 abundant blood plasma proteins. The addition of UF did not improve the purity of samples based on peptide ID of common blood contaminants, however it did result in significant loss of common EV markers and EX-related proteins as described in the enrichment analysis. Based on the findings of this study, the recommendation for EX enrichment from blood plasma for downstream proteomics analysis is UC+SEC followed by a modified FASP protocol, for optimum EX yield, purity, protein ID and EX-associated proteins. If sample pooling is necessary, consideration should be given to the performing WB analysis prior to pooling to confirm the relative abundance of BSA in EX fractions.

The obvious benefit of the UC+SEC method is its large starting volume compared to SEC, which improves overall particle yield dramatically. However, it is clear from this study that even when starting with small volumes of plasma, MS can be successfully applied to identify a significant number of proteins in EX enriched samples. Interestingly, the order in which enrichment strategies SEC and UC are performed affects the mean and mode sizes of the particles obtained. Furthermore, we identified LGALS3BP in all enrichment methods and not in the plasma control sample. This protein is known to be enriched in exomeres, suggesting the co-isolation of this EV subtype in all methods utilised in this study. LGALS3BP warrants further investigation as a possible candidate for direct immunocapture, which would simplify exomere enrichment from blood plasma if desired (36). 

Therefore, the reproducibility of this process is likely to be user-dependent, especially when performing two or more fractionations simultaneously to improve sample throughput. This was demonstrated in a recent study where higher inter-sample variation occurred using SEC columns as opposed to exoEasy and ExoQuick (32). Additionally, if high sample purity is of specific importance to the study, then WB for selected plasma proteins should be performed prior to EX fraction pooling. In this study, the amount of BSA present in the UC+SEC pooled sample did not appear to have a detrimental effect on the number of EX proteins identified compared to the other methods. The consequence of omitting an EX fraction due to increased BSA presence must be weighed against the loss of a significant portion of EX particles, which may have a deleterious effect on the number of protein IDs or quantitation of proteins if performing quantitative proteomics studies (21).

UC+SEC enriches for larger particles than SEC and SEC+UC.

The order of EX enrichment method affects the size of the EX particles obtained. Although EX are still within the expected size range, it is of interest as to whether performing UC prior to SEC further enriches for a specific subpopulation of EX in the upper size range, thus introducing bias. EX size difference has been used successfully as a prognostic for disease and thus is of interest in biomarker studies $(37,38)$. It has already been established that UC performed independently on blood plasma coisolates particles in the $20-250 \mathrm{~nm}$ size range, while SEC isolates particles of diameter $20-200 \mathrm{~nm}$ (39). This is supported by a separate study that confirmed EVs isolated from cell culture media by UF+SEC contained fewer particles $>200 \mathrm{~nm}$ than UC alone (40). UC is known to result in both EX and protein aggregation as a result of extended periods of high centrifugal force (41). Therefore, commencing EX-enrichment with UC likely co-isolates larger particles initially and explains their increased presence in the final EX-enriched sample resulting from UC+SEC. This is also likely the cause of the difference in particle elution profiles observed between SEC and UC+SEC in the current study. Indeed, TEM images did not display a noticeable size difference in EX particles between methods but rather an increase of aggregates and non-EX material in EX pooled 7-10 UC+SEC and UC+SEC+UF fractions. The presence of non-EX particles in EX-enriched samples resulting from UC+SEC+/-UF is something to take into account when performing particle size analysis. Results should be interpreted with caution and always compared to particle visualisation by TEM or similar techniques.

The formation of EX and protein aggregates following UC should be considered carefully if the intention is to follow it with further enrichment by SEC. Disruption of aggregates prior to SEC may yield purer fractions containing less BSA or other unwanted plasma proteins. Reduction of aggregates may also give better separation of EV particles and improve EX particle yield, given that optimal fractionation depends almost entirely on particle size. BSA is $\sim 3 \mathrm{~nm}$ in diameter, therefore increased BSA contamination of EX fraction 7 in UC+SEC method indicates significant BSA protein aggregation, causing it to elute in a fraction that theoretically should have contained particles of diameter $100-$ $200 \mathrm{~nm}$. Methods to disrupt aggregates should also be employed with care in regard to downstream analyses. Digestion of unwanted proteins by treating with proteases may compromise EX surfacebound proteins or the external domains of membrane proteins $(23,42)$. Likewise, extended periods of sonication could degrade EX proteins or cause leakage and loss of internal EX components into the external milieu (43). 
pathways from blood plasma is critical to ongoing research in these areas. EX have been implicated in the regulation of neurodegenerative diseases such as Huntington's and Alzheimer's Diseases, and promote metastasis via the Wnt, Cadherin and Integrin signalling pathways in various types of cancer (44-48). Similarly, EX release from cells in response to DNA damage is under the control of p53-driven gene expression, and EX-derived miRNA are essential for mutant p53-associated oncogenesis (49). Furthermore, the stimulation of cholecystokinin receptors (CCKR) have been shown to increase the release of EVs by more than 2-fold in human and mouse trophoblast cell lines (50). The increased presence of proteins associated with these pathways in EX-enriched samples suggests that it is possible to isolate these EX-populations in peripheral blood plasma, which could be of utility in clinical studies. However, the enrichment of proteins involved in these pathways was not consistent across each method in this study. Overall, UC+SEC was the most consistent in identifying proteins involved in all EX-related pathways assessed in this study. However, if the aim is to isolate vesicles for a specific pathway of interest, thought should be given to the choice of isolation method, as this will likely affect the success of enrichment for the desired subset of proteins.

\section{The method of EX enrichment has a direct impact on protein ID.}

In protein biomarker studies the quality of the sample is paramount to the success of the project. We have shown that the method of EX enrichment strategy is critical for the depletion of blood plasma proteins and the optimal ID of EX-associated proteins. UC+SEC was the superior method for providing the best particle yield, purity, protein ID and EX marker ID. This is consistent with a previous study that determined UC+SEC was an efficient method for optimum particle yield (19). SEC+UC was the most effective technique in depleting the number of blood plasma proteins by peptide ID, although blood coagulation components accounted for over $44 \%$ of the total number of proteins. However, this is likely due to SEC+UC yielding the lowest number of proteins out of the four EX isolation and enrichment methods in this study. While 251 proteins were identified in SEC+UF (1\% FDR), the number of top 100 EX markers represented only $3.2 \%$ of the total number of proteins identified in this method. In comparison, only 81 proteins were identified in total by SEC+UC method, however the number of top 100 EX markers represented $4.9 \%$ of the total. Finally, the top 100 EX markers identified in UC+SEC accounted for $8.9 \%$ of the total number of proteins. It is therefore clear that the discernment of EV or EX proteins from the total number of proteins identified is key to confirming whether the enrichment method was effective in a) enriching for EX and, b) depleting highly abundant plasma proteins contained in the original biofluid. Additionally, UC+SEC method improved the number of EX proteins identified as per ExoCarta and Vesiclepedia compared to separate studies that used at least one of the commercially available kits ExoSpin and ExoQuick to isolate EX from human plasma $(32,51)$. As a species-specific database for blood plasma EX has not yet been established, and many of the proteins identified by each method are yet to be fully characterised (e.g., 247 proteins were identified in UC+SEC method, of which 173 were mapped), there are potentially many more EX proteins present than what were able to be identified $(52,53)$. The 21 proteins unique to EX identified in UC+SEC that were not listed in the Vesiclepedia are also an example of this, as GO analysis evidenced their association with EX-related processes, however these proteins are currently unreviewed in Uniprot (https://www.uniprot.org/).

Interestingly, the proteins FLOT-1 and TSG101 that are frequently used as EX markers were not detected in any of the isolation and enrichment methods under study by MS. The absence of FLOT-1 from EX-enriched samples produced by all methods was confirmed by WB, which suggests enrichment may not be possible using the methods described in this study. FLOT-1 has previously been identified in human plasma by WB analysis following immunocapture of CD9- and CD81-positive EX (13). The same study also demonstrated that TSG101 was not present in blood plasma EX, thus it may be cell- 
type specific and not released into systemic circulation (13). A more recent methodological evaluation study using ExoQuick, exoEasy, SEC and OptiPrep also failed to detect FLOT-1 by MS in human blood plasma (32). Whether a targeted strategy is required for enrichment of FLOT-1 EX populations is unclear, however, the four isolation and enrichment methods utilised in this study were unsuccessful in isolating EX that contain FLOT-1 in sufficient amount for detection. An alternative approach would be direct immunocapture of specific EX markers of interest to further explore EV subpopulations, as non-specific methods co-isolate many non-EV particles, as is the case in this and many other studies. The data presented here merely provides an overview of the feasibility of performing MS analysis of EX using different methods of enrichment and purification.

The ID of LGALS3BP in all EX-enrichment methods utilised in this study is a novel finding. LGALS3BP has previously been identified in human and animal studies from blood plasma or cell cultureconditioned media using UC with iodixanol gradient or EX isolation kits (ExoSpin/ExoQuick) $(51,54)$. Zhang and colleagues (2019) were the first to attribute enrichment of the LGALS3BP, a sialoglycoprotein protein, in the EV subclass exomeres (diameter $\sim 35 \mathrm{~nm}$ ) via asymmetric field flow fractionation of cancer cell lines (38). Subsequently, exomeres have been successfully isolated by a modified sequential UC method, thus the ease in which they can be studied has improved (36). In addition to being linked to glycosylation modulation and protein folding, exomeres are also enriched with metabolic proteins and proteins associated with neurological diseases such as Alzheimer's and Parkinson's Diseases $(12,36)$. Proteins associated with these disease pathways were indeed enriched in EX samples produced in this study as previously mentioned. As exomeres have been found to coisolate with EX in this and other studies using a standard differential centrifugation method for enrichment, it is of interest as to whether the origin of many 'EX' proteins may in fact be exomerederived. While studies involving exomeres have provided valuable information regarding their characteristics and functions, very little is known regarding their biogenesis, or whether their function in systemic circulation i.e. blood plasma is similar to that of cell-derived exomeres (55). It is outside the scope of this project to determine the number of exomeres within our exo-enriched samples, however future studies may wish to determine the proportion of exomeres in heterogenous EV and/or EX samples, and whether they have any association with health and disease.

\section{Conclusions}

It is now widely accepted that EX populations differ depending on the cell type or biofluid of origin $(12,13,56,57)$. To our knowledge, this is the first study to identify a significant difference in the mean and mode sizes of EX based on whether UC was performed before or after SEC. Numerous studies have provided size data for individual enrichment strategies, but did not compare the effects on size distribution following multiple enrichment methods performed in distinct orders $(20,58,59)$. Blood plasma is especially challenging as a biofluid, as vesicles shed directly into the bloodstream making ID of the cell-type of origin nearly impossible without the use of a cell-specific marker to identify an EX population of interest. Even in the case where an appropriate antibody can be used for direct immunocapture, prior removal of blood plasma proteins via EX enrichment methods is still required for optimum yield and purity due to cross-reactivity with plasma proteins (60). It is useful to know that UF as an EX sample clean-up method is not recommended for downstream proteomics analysis due to the significant amount of EX protein loss that occurs, even with a low molecular weight cut-off filter, as was used in this study.

Importantly, an EX database specifically for livestock animals has not yet been established. A species search is possible using ExoCarta and Vesiclepedia, however in Bos taurus many of these proteins have been identified in milk, not blood plasma. Vesiclepedia currently has no listings for EX proteins identified in the blood plasma of dairy cows. We have provided evidence that a significant portion of 
the top 100 and above EX proteins listed in predominantly human EX databases ExoCarta and Vesiclepedia are also present in the blood plasma of cow species Bos taurus. This is a critical finding as it suggests the roles of EX are conserved across mammalian species and highlights their biological significance.

\section{Acknowledgements}

We would like to thank Rebecca Fieth at CARF microscopy lab for her time and effort performing the TEM imaging. We would also like to thank Raj Gupta at CARF mass spectrometry lab for his time and assistance in running EX samples. NT is supported by a student scholarship from the Australian Research Council (Grant No: ARC LP160101854) and QUT HDR Tuition fee sponsorship. Our laboratory experiments were funded, in part, by funding from a partnership fund (DRCX1302) between the New Zealand Ministry of Business, Innovation and Employment and New Zealand dairy farmers through 798 DairyNZ Inc.

\section{Additional information}

800 Competing interest statement

801 The authors declare no competing interests.

802 Data accessibility statement

803 The authors confirm that the data supporting the findings of this study are available within the article 804 and its supplementary materials.

\section{Abbreviations}

$\begin{array}{ll}\text { BCA } & \text { Bicinchoninic acid } \\ \text { BSA } & \text { Bovine serum albumin } \\ \text { DDA } & \text { Data-dependent acquisition } \\ \text { DPBS } & \text { Dulbecco's phosphate buffered saline } \\ \text { EV } & \text { Extracellular vesicle } \\ \text { EX } & \text { Exosomes/exosomal } \\ \text { FASP } & \text { Filter aided sample preparation } \\ \text { FDR } & \text { False discovery rate } \\ \text { FLOT-1 } & \text { Flotillin-1 } \\ \text { ID } & \text { Identification } \\ \text { LDL } & \text { Low-density lipoprotein } \\ \text { LGALS3BP } & \text { Galectin-3 binding protein } \\ \text { MS } & \text { Mass spectrometry } \\ \text { Non-EX } & \text { Non-exosomal } \\ \text { NTA } & \text { Nanoparticle tracking analysis } \\ \text { PBS } & \text { Phosphate buffered saline } \\ \text { PBST } & \text { Phosphate buffered saline and 0.1\% Tween-20 } \\ \text { SDC } & \text { Sodium deoxycholate } \\ \text { SEC } & \text { Size-exclusion chromatography } \\ \text { TEM } & \text { Transmission electron microscopy } \\ \text { TFA } & \text { Trifluoroacetic acid } \\ \text { TOF } & \text { Time-of-flight } \\ \text { TSG101 } & \text { Tumour susceptibility gene 101 } \\ \text { UC } & \text { Ultracentrifugation } \\ \text { UF } & \text { Ultrafiltration } \\ & \end{array}$


Western blot

806 
1. Wiśniewski JR, Zougman A, Nagaraj N, Mann M. Universal sample preparation method for proteome analysis. Nat Methods. 2009;6(5):359-62.

2. Collins BC, Hunter CL, Liu Y, Schilling B, Rosenberger G, Bader SL, et al. Multi-laboratory assessment of reproducibility, qualitative and quantitative performance of SWATH-mass spectrometry. Vol. 8, Nature Communications. 2017.

3. Zhang Y, Liu Y, Liu H, Tang WH. Exosomes: biogenesis, biologic function and clinical potential. Cell Biosci [Internet]. 2019/03/01. 2019;9:19. Available from: https://www.ncbi.nlm.nih.gov/pubmed/30815248

4. Nazimek K, Bryniarski K, Santocki M, Ptak W. Exosomes as mediators of intercellular communication: Clinical implications. Pol Arch Med Wewn. 2015;125(5):370-80.

5. Record M, Carayon K, Poirot M, Silvente-Poirot S. Exosomes as new vesicular lipid transporters involved in cell-cell communication and various pathophysiologies [Internet]. Vol. 1841, Biochimica et Biophysica Acta - Molecular and Cell Biology of Lipids. Biochim Biophys Acta; 2014 [cited 2020 Jul 9]. p. 108-20. Available from: https://pubmed.ncbi.nlm.nih.gov/24140720/

6. Dai J, Su Y, Zhong S, Cong L, Liu B, Yang J, et al. Exosomes: key players in cancer and potential therapeutic strategy. Signal Transduct Target Ther [Internet]. 2020;5(1). Available from: http://dx.doi.org/10.1038/s41392-020-00261-0

7. Doyle LM, Wang MZ. Overview of Extracellular Vesicles, Their Origin, Composition, Purpose, and Methods for Exosome Isolation and Analysis. Cells. 2019;8(727):1-24.

8. Mashouri L, Yousefi H, Aref AR, Ahadi AM, Molaei F, Alahari SK. Exosomes: Composition, biogenesis, and mechanisms in cancer metastasis and drug resistance. Mol Cancer. 2019;18(1):1-14.

9. Rashed MH, Bayraktar E, Helal GK, Abd-Ellah MF, Amero P, Chavez-Reyes A, et al. Exosomes: From garbage bins to promising therapeutic targets [Internet]. Vol. 18, International Journal of Molecular Sciences. MDPI AG; 2017 [cited 2020 Jul 16]. Available from: https://pubmed.ncbi.nlm.nih.gov/28257101/

10. Li X, Corbett AL, Taatizadeh E, Tasnim N, Little JP, Garnis C, et al. Challenges and opportunities in exosome research-Perspectives from biology, engineering, and cancer therapy. APL Bioeng [Internet]. 2019;3(1):1-21. Available from: http://dx.doi.org/10.1063/1.5087122

11. Konoshenko MY, Lekchnov EA, Vlassov A V., Laktionov PP. Isolation of Extracellular Vesicles: General Methodologies and Latest Trends. Biomed Res Int. 2018;2018.

12. Zhang H, Freitas D, Kim HS, Fabijanic K, Li Z, Chen H, et al. Identification of distinct nanoparticles and subsets of extracellular vesicles by asymmetric flow field-flow fractionation. Nat Cell Biol [Internet]. 2018 Mar 19;20(3):332-43. Available from: http://www.nature.com/articles/s41556-018-0040-4

13. Jeppesen DK, Fenix AM, Franklin JL, Higginbotham JN, Zhang Q, Zimmerman L, et al. Reassessment of Exosome Composition. Cell [Internet]. 2019;177(2):428-445.e18. Available from: https://doi.org/10.1016/j.cell.2019.02.029

14. Chen $Y$, Zhu $Q$, Cheng $L$, Wang $Y$, Li M, Yang $Q$, et al. Exosome detection via the ultrafastisolation system: EXODUS. Nat Methods [Internet]. 2021;18(2):212-8. Available from: http://dx.doi.org/10.1038/s41592-020-01034-x 
15. Witwer KW, Buzás El, Bemis LT, Bora A, Lässer C, Lötvall J, et al. Standardization of sample collection, isolation and analysis methods in extracellular vesicle research. J Extracell Vesicles. 2013;2(1):1-25.

16. Dong L, Zieren RC, Horie K, Kim CJ, Mallick E, Jing Y, et al. Comprehensive evaluation of methods for small extracellular vesicles separation from human plasma, urine and cell culture medium. J Extracell Vesicles. 2020;10(2).

17. Madhavan B, Yue S, Galli U, Rana S, Gross W, Müller M, et al. Combined evaluation of a panel of protein and miRNA serum-exosome biomarkers for pancreatic cancer diagnosis increases sensitivity and specificity. Int J Cancer [Internet]. 2015 Jun 1;136(11):2616-27. Available from: http://doi.wiley.com/10.1002/ijc.29324

18. Lobb RJ, Becker M, Wen SW, Wong CSF, Wiegmans AP, Leimgruber A, et al. Optimized exosome isolation protocol for cell culture supernatant and human plasma. J Extracell Vesicles. 2015;4(1):1-11.

19. Koh YQ, Almughlliq FB, Vaswani K, Peiris HN, Mitchell MD. Exosome enrichment by ultracentrifugation and size exclusion chromatography. Front Biosci (Landmark Ed [Internet]. 2018;23:865-74. Available from: http://www.ncbi.nlm.nih.gov/pubmed/28930577

20. Martins TS, Catita J, Rosa IM, Da Cruz e Silva OAB, Henriques AG. Exosome isolation from distinct biofluids using precipitation and column-based approaches. PLoS One. 2018;13(6):116.

21. Pietrowska M, Wlosowicz A, Gawin M, Widlak P. MS-Based Proteomic Analysis of Serum and Plasma: Problem of High Abundant Components and Lights and Shadows of Albumin Removal. In: Capelo-Martínez J-L, editor. Emerging Sample Treatments in Proteomics. Springer Nature Switzerland; 2019. p. 57-76.

22. Pietrowska M, Funk S, Gawin M, Marczak $Ł$, Abramowicz A, Widłak $P$, et al. Isolation of exosomes for the purpose of protein cargo analysis with the use of mass spectrometry. Methods Mol Biol. 2017;1654:291-307.

23. Diaz G, Bridges C, Lucas M, Cheng Y, Schorey JS, Dobos KM, et al. Protein digestion, ultrafiltration, and size exclusion chromatography to optimize the isolation of exosomes from human blood plasma and serum. J Vis Exp. 2018;2018(134):1-6.

24. Raimondo F, Morosi L, Chinello C, Magni F, Pitto M. Advances in membranous vesicle and exosome proteomics improving biological understanding and biomarker discovery. Proteomics. 2011;11(4):709-20.

25. Crookenden MA, Walker CG, Peiris H, Koh Y, Heiser A, Loor JJ, et al. Short communication: Proteins from circulating exosomes represent metabolic state in transition dairy cows. J Dairy Sci [Internet]. 2016;99(9):7661-8. Available from: https://linkinghub.elsevier.com/retrieve/pii/S0022030216303691

26. Koh YQ, Peiris HN, Vaswani K, Meier S, Burke CR, Macdonald KA, et al. Characterization of exosomes from body fluids of dairy cows. J Anim Sci. 2017;95(9):3893-904.

27. Almughlliq FB, Koh YQ, Peiris HN, Vaswani K, McDougall S, Graham EM, et al. Proteomic content of circulating exosomes in dairy cows with or without uterine infection. Theriogenology [Internet]. 2018;114:173-9. Available from: https://doi.org/10.1016/j.theriogenology.2018.03.024

28. Meier S, Fisher B, Eketone K, McNaughton L, Amer P, Beatson P, et al. Calf and heifer development and the onset of puberty in dairy cows with divergent genetic merit for fertility. 
29. Bowley FE, Green RE, Amer PR, Meier S. Novel approaches to genetic analysis of fertility traits in New Zealand dairy cattle. J Dairy Sci [Internet]. 2015;98(3):2005-12. Available from: http://dx.doi.org/10.3168/jds.2014-8266

30. Yudasaka M, Yomogida Y, Zhang M, Nakahara M, Kobayashi N, Tanaka T, et al. Fastingdependent Vascular Permeability Enhancement in Brown Adipose Tissues Evidenced by Using Carbon Nanotubes as Fluorescent Probes. Sci Rep [Internet]. 2018 Dec 27;8(1):14446. Available from: http://dx.doi.org/10.1038/s41598-018-32758-8

31. Oh JG, Lee P, Gordon RE, Sahoo S, Kho C, Jeong D. Analysis of extracellular vesicle miRNA profiles in heart failure. J Cell Mol Med [Internet]. 2020 Jul 2;24(13):7214-27. Available from: https://onlinelibrary.wiley.com/doi/10.1111/jcmm.15251

32. Veerman RE, Teeuwen L, Czarnewski P, Güclüler Akpinar G, Sandberg A, Cao X, et al. Molecular evaluation of five different isolation methods for extracellular vesicles reveals different clinical applicability and subcellular origin. J Extracell Vesicles [Internet]. $2021 \mathrm{Jul}$ 22;10(9). Available from: https://onlinelibrary.wiley.com/doi/10.1002/jev2.12128

33. Walton JR, Frey HA, Vandre DD, Kwiek JJ, Ishikawa T, Takizawa T, et al. Expression of flotillins in the human placenta: potential implications for placental transcytosis. Histochem Cell Biol [Internet]. 2013 Mar 14;139(3):487-500. Available from: http://link.springer.com/10.1007/s00418-012-1040-2

34. Jung MK, Mun JY. Sample Preparation and Imaging of Exosomes by Transmission Electron Microscopy. J Vis Exp [Internet]. 2018 Jan 4;(131). Available from:

https://www.jove.com/video/56482/sample-preparation-imaging-exosomes-transmissionelectron

35. Porter JJ, Wildsmith J, Melm CD, Schuchard MD, Ray KM, Chen DE, et al. Absolute Quantification of the Lower Abundance Proteome Through Immunoaffinity Depletion of the Twenty Most Abundant Proteins in Human Serum. Sigma-Adrich Tech Note. 2006;3-4.

36. Zhang Q, Higginbotham JN, Jeppesen DK, Yang YP, Li W, McKinley ET, et al. Transfer of Functional Cargo in Exomeres. Cell Rep [Internet]. 2019;27(3):940-954.e6. Available from: https://doi.org/10.1016/j.celrep.2019.01.009

37. Navarro A, Molins L, Marrades RM, Moises J, Viñolas N, Morales S, et al. Exosome analysis in tumor-draining pulmonary vein identifies NSCLC patients with higher risk of relapse after curative surgery. Cancers (Basel). 2019;11(2):1-11.

38. Zhang H, Freitas D, Kim HS, Fabijanic K, Li Z, Chen H, et al. Identification of distinct nanoparticles and subsets of extracellular vesicles by asymmetric flow field-flow fractionation. Nat Cell Biol [Internet]. 2018 Mar 19;20(3):332-43. Available from: http://dx.doi.org/10.1038/s41556-018-0040-4

39. Sidhom K, Obi PO, Saleem A. A Review of Exosomal Isolation Methods: Is Size Exclusion Chromatography the Best Option? Int J Mol Sci [Internet]. 2020 Sep 4;21(18):6466. Available from: https://www.mdpi.com/1422-0067/21/18/6466

40. Benedikter BJ, Bouwman FG, Vajen T, Heinzmann ACA, Grauls G, Mariman EC, et al. Ultrafiltration combined with size exclusion chromatography efficiently isolates extracellular vesicles from cell culture media for compositional and functional studies. Sci Rep [Internet]. 2017;7(1):1-13. Available from: http://dx.doi.org/10.1038/s41598-017-15717-7

41. Linares R, Tan S, Gounou C, Arraud N, Brisson AR. High-speed centrifugation induces 
aggregation of extracellular vesicles. J Extracell Vesicles [Internet]. 2015 Jan 1;4(1):29509. Available from: https://www.tandfonline.com/doi/full/10.3402/jev.v4.29509

42. Cvjetkovic A, Jang SC, Konečná B, Höög JL, Sihlbom C, Lässer C, et al. Detailed Analysis of Protein Topology of Extracellular Vesicles-Evidence of Unconventional Membrane Protein Orientation. Sci Rep [Internet]. 2016 Dec 8;6(1):36338. Available from: http://www.nature.com/articles/srep36338

43. Abramowicz A, Marczak L, Wojakowska A, Zapotoczny S, Whiteside TL, Widlak P, et al. Harmonization of exosome isolation from culture supernatants for optimized proteomics analysis. Ahmad A, editor. PLoS One [Internet]. 2018 Oct 31;13(10):e0205496. Available from: https://dx.plos.org/10.1371/journal.pone.0205496

44. Tang MKS, Yue PYK, Ip PP, Huang R-L, Lai H-C, Cheung ANY, et al. Soluble E-cadherin promotes tumor angiogenesis and localizes to exosome surface. Nat Commun [Internet]. $2018 \mathrm{Dec}$ 11;9(1):2270. Available from: http://dx.doi.org/10.1038/s41467-018-04695-7

45. Działo E, Rudnik M, Koning R, Czepiel M, Tkacz K, Baj-Krzyworzeka M, et al. WNT3a and WNT5a Transported by Exosomes Activate WNT Signaling Pathways in Human Cardiac Fibroblasts. Int J Mol Sci [Internet]. 2019 Mar 21;20(6):1436. Available from: https://www.mdpi.com/1422-0067/20/6/1436

46. Hu Y-B, Yan C, Mu L, Mi Y -L., Zhao H, Hu H, et al. Exosomal Wnt-induced dedifferentiation of colorectal cancer cells contributes to chemotherapy resistance. Oncogene [Internet]. 2019 Mar 2;38(11):1951-65. Available from: http://www.nature.com/articles/s41388-018-0557-9

47. Shimaoka M, Kawamoto E, Gaowa A, Okamoto T, Park EJ. Connexins and integrins in exosomes. Cancers (Basel). 2019;11(1).

48. Howitt J, Hill AF. Exosomes in the Pathology of Neurodegenerative Diseases. J Biol Chem [Internet]. 2016/11/18. 2016;291(52):26589-97. Available from: https://www.ncbi.nlm.nih.gov/pubmed/27852825

49. Yu X, Harris SL, Levine AJ. The regulation of exosome secretion: A novel function of the p53 protein. Vol. 66, Cancer Research. 2006. p. 4795-801.

50. Conrad KP, Tuna KM, Mestre CT, Banwatt ES, Alli AA. Activation of multiple receptors stimulates extracellular vesicle release from trophoblast cells. Vol. 8, Physiological Reports. 2020.

51. Sundar IK, Li D, Rahman I. Proteomic Analysis of Plasma-Derived Extracellular Vesicles in Smokers and Patients with Chronic Obstructive Pulmonary Disease. ACS Omega [Internet]. 2019 Jun 30;4(6):10649-61. Available from: https://pubs.acs.org/doi/10.1021/acsomega.9b00966

52. Mathivanan S, Simpson RJ. ExoCarta: A compendium of exosomal proteins and RNA. Proteomics [Internet]. 2009 Nov 1;9(21):4997-5000. Available from: https://doi.org/10.1002/pmic.200900351

53. Pathan M, Fonseka P, Chitti S V., Kang T, Sanwlani R, Van Deun J, et al. Vesiclepedia 2019: a compendium of RNA, proteins, lipids and metabolites in extracellular vesicles. Nucleic Acids Res [Internet]. 2019 Jan 8;47(D1):D516-9. Available from: https://academic.oup.com/nar/article/47/D1/D516/5160990

54. Koh YQ, Peiris HN, Vaswani K, Reed S, Rice GE, Salomon C, et al. Characterization of exosomal release in bovine endometrial intercaruncular stromal cells. Reprod Biol Endocrinol.

2016;14(1):1-21. 
1000

1001

1002

1003

1004

1005

1006

1007

1008

1009

1010

1011

1012

1013

1014

1015

1016

1017

1018

1019

1020

1021

1022

55. Zijlstra A, Di Vizio D. Size matters in nanoscale communication. Nat Cell Biol [Internet]. 2018 Mar 23;20(3):228-30. Available from: http://www.nature.com/articles/s41556-018-0049-8

56. Kowal J, Arras G, Colombo M, Jouve M, Morath JP, Primdal-Bengtson B, et al. Proteomic comparison defines novel markers to characterize heterogeneous populations of extracellular vesicle subtypes. Proc Natl Acad Sci U S A. 2016;113(8):E968-77.

57. Zheng H, Guan S, Wang X, Zhao J, Gao M, Zhang X. Deconstruction of Heterogeneity of SizeDependent Exosome Subpopulations from Human Urine by Profiling N-Glycoproteomics and Phosphoproteomics Simultaneously. Anal Chem. 2020;92(13):9239-46.

58. Lobb RJ, Becker M, Wen SW, Wong CSF, Wiegmans AP, Leimgruber A, et al. Optimized exosome isolation protocol for cell culture supernatant and human plasma. J Extracell Vesicles. 2015;4(1).

59. Brennan K, Martin K, FitzGerald SP, O'Sullivan J, Wu Y, Blanco A, et al. A comparison of methods for the isolation and separation of extracellular vesicles from protein and lipid particles in human serum. Sci Rep. 2020;10(1):1-13.

60. Sharma P, Ludwig S, Muller L, Hong CS, Kirkwood JM, Ferrone S, et al. Immunoaffinity-based isolation of melanoma cell-derived exosomes from plasma of patients with melanoma. J Extracell Vesicles [Internet]. 2018 Dec 1;7(1):1435138. Available from: https://doi.org/10.1080/20013078.2018.1435138

\section{Author Contributions Statement}

Conceptualization, N.T. and M.D.M.; investigation, N.T.; writing-original draft preparation, N.T.; writing-review and editing, P.S., J.L., K.V., K.A.K.C., P.A., and M.D.M.; visualization, N.T.; supervision, J.L., P.S., and M.D.M. All authors have read and agreed to the published version of the manuscript.

\section{Legends}

Figure 1: Workflow for EX enrichment methods 1-4.

Figure 2: Western blot of bovine serum albumin (BSA) in SEC (A) and UC+SEC (B) fractions. $L=$ ladder; $C=$ Control, 1 ug purified BSA; $B=$ blank; 7, 8, 9, 10, 11, 12, 13, 14, 15, 16, 1-6 = individual EX (7 - 10), non-EX (11 - 16) fractions, and void volume fractions pool (1 -6). Predicted molecular weight of BSA = $69 \mathrm{kDa}$. (Full length blot images available in Supplementary file 2, Figures S1 and S2.)

Figure 3A - C: Western blot of Flotillin-1 (FLOT-1). A - C: L = ladder; +ve = positive control, $2.5 \mu \mathrm{g} \mathrm{JEG-}$ 3 cell lysate; -ve = negative control, $5 \mu \mathrm{L}$ de-ionized $\mathrm{H}_{2} \mathrm{O}$. A and $\mathrm{B}$ : As annotated for each method, evennumbered lanes $=$ pooled EX fractions $7-10$ resulting from SEC. Odd-numbered lanes $=$ pooled nonEX fractions $11-16$ resulting from SEC. C: Lane 4; pooled EX $7-10$ fractions for all replicates; lane 5 $=$ pooled non-EX fractions $11-16$ for all replicates. Predicted molecular weight of FLOT-1 $=47 \mathrm{kDa}$. (Full length blot images available in Supplementary file 2, Figures S3 - 5.)

Figure 4: A) Particle concentration (particles $/ \mathrm{mL}$ ) distribution of SEC and UC+SEC fractions 1-6 (pool) and 7-16 individual fractions. Peak concentration of particles in EX fractions 7-10 occurs in fraction 10 in SEC, and fraction 7 in UC+SEC. B) Mean and mode size distributions of SEC and UC+SEC fractions 1-6 (pool) and individual fractions 7-16. All particles in EX fractions 7-10 fell within small EV range 
$(<200 \mathrm{~nm})$. The mode size of SEC particles in EX fractions 7 - 10 ranged from $90-110$. The mode size of UC+SEC particles in EX fractions $7-10$ ranged from $\sim 120-170 \mathrm{~nm}$. C) Mean and mode size distributions of SEC+UC and UC+SEC pooled EX 7- 10 fractions. In both mean and mode size analysis, UC+SEC particles were significantly larger than those obtained by SEC+UC $\left(n=4,+/-\operatorname{SEM} ;{ }^{*} p<0.05\right)$.

Figure 5A and B: Representative TEM images of pooled EX fractions 7-10 by each of the four methods of EX isolation and enrichment. A: Widefield view of EX fractions $7-10$. B: Single particle views of EX fractions $7-10$. Colour legend for circled particles in A: orange, $<75 \mathrm{~nm}$; red, $75-150 \mathrm{~nm}$; green, $>150 \mathrm{~nm}$.

Figure 6: Venn diagram of proteins unique to and shared by the four EX isolation and enrichment methods under study and plasma control.

Figure 7: Percentage of top 100 EV proteins (Vesiclepedia and ExoCarta) identified in EX enriched samples by all methods.

Figure 8: Summary plot of mapped EV and non-EV proteins in the four methods under study identified in the Vesiclepedia complete database and plasma control. EV proteins = identified in samples and Vesiclepedia database; Plasma = identified in plasma and EX-enriched sample; Other = identified in EX-enriched sample only.

Figure 9: Functional enrichment analysis (cellular component) of detected proteins in plasma processed using one of the four methods for EX protein enrichment and plasma control.

Table 1: Number of proteins identified in EX enrichment methods. Proteins at $1 \%$ FDR, peptides at $5 \%$ FDR, with minimum 2 peptides per protein.

Table 2: Proportion of peptides identified in EX enriched samples compared to a plasma control. Green indicates a decrease and red an increase in peptides identified by one of the four EX enrichment methods compared to a plasma control (plasma $=1$ ). 


\section{Supplementary Files}

This is a list of supplementary files associated with this preprint. Click to download.

- Supplementaryfile1collatedMSresultsseqcoveragepeptidelDmasserrors.xIsx

- Supplementaryfile2.pdf

- Supplementaryfile3UCSECpantherGO.xIsx

- Supplementaryfile4UCSECUFpantherGO.xIsx

- Supplementaryfile5ProteinpilotoutputSECUCFDR.xIsx

- Supplementaryfile6ProteinpilotoutputSECUFFDR.xlsx

- Supplementaryfile7ProteinpilotoutputUCSECFDR.xlsx

- Supplementaryfile8ProteinpilotoutputUCSECUFFDR.xlsx 